\title{
Quantitative Evaluation and Case Study of Risk Degree for Underground Goafs with Multiple Indexes considering Uncertain Factors in Mines
}

\author{
Longjun Dong, Weiwei Shu, Xibing Li, Zilong Zhou, Fengqiang Gong, and XiLing Liu \\ School of Resources and Safety Engineering, Central South University, Changsha 410083, China \\ Correspondence should be addressed to Longjun Dong; lj.dong@csu.edu.cn
}

Received 23 June 2017; Accepted 14 September 2017; Published 16 October 2017

Academic Editor: Xiaoqing Shi

Copyright (C) 2017 Longjun Dong et al. This is an open access article distributed under the Creative Commons Attribution License, which permits unrestricted use, distribution, and reproduction in any medium, provided the original work is properly cited.

\begin{abstract}
The accidents caused by underground goafs are frequent and destructive due to irregular geometric shapes and complex spatial distributions, which caused severe damage to the environment and public health. Based on the theories of uncertainty measurement evaluation (WME) and analytic hierarchy process (AHP), the comprehensive risk evaluation of underground goafs was carried out using multiple indexes. Considering the hydrogeological conditions, mining status, and engineering parameters of underground goafs, the evaluation index system was established to evaluate the risk degrees considering quantified uncertain factors. The single index measurement values were solved by the semiridge measurement function. The weights for evaluation vectors were calculated through the entropy theory and AHP. Finally, the risk level was evaluated according to the credible degree recognition criterion (CDRC) and the maximum membership principle. The risk levels of 37 underground goafs in Dabaoshan mine were evaluated using 4 coupled methods. The order for underground goafs risk degrees was ranked and classified on account of the uncertainty important degree. According to the ranked order, the reasonability of 4 coupled methods was evaluated quantitatively. Results show that the UME-CDRC can be applied in the practical engineering, which provides an efficient guidance to both reduce the accident risk and improve the mining environment.
\end{abstract}

\section{Introduction}

Underground mining projects are the basic energy source and resource guarantee of the national economic development. The mining industry develops rapidly in the countries like South Africa, Australia, Canada, Poland, and China. With the large land area and relatively small population, it is viable to carry out the open pit mining in Australia and Canada, where little underground goafs are distributed [1-4]. Compared to these countries, a large number of underground goafs formed in the process of mining in China, especially in the underground mines using open stope mining methods [5-7]. Since the 1980s, the illegal mining was rising up in China, which caused numerous unknown underground goafs around the mines. There is no doubt that they present a very serious threat to safety and viability of efficient and sustainable mining, due to the characteristics of irregular geometric shapes, complex spatial distributions, and being strongly concealed [8-10].

In recent years, many collapse accidents of underground goafs have occurred, which have caused huge economic losses, casualties, and serious ecological damage. Particularly, the damage to our vegetation, water, and land from numerous underground goafs induced by large-scale mining has posed severe threats to the environment and public health [1117]. There are more than 9000 state-owned mines in China. The annual amount of mineral production has reached 9 billion tons and the volume of underground goafs has reached billions of cubic meters. In Shanxi Province, the area of underground goafs has been as large as $1 / 8$ of the whole provincial area. Numerous mines in China are mining with underground goafs, including Dachang mine, Changba leadzinc mine, Shizishan copper mine, Luanchuan molybdenum mine, Lanping lead-zinc mine, and Dabaoshan mine. The 


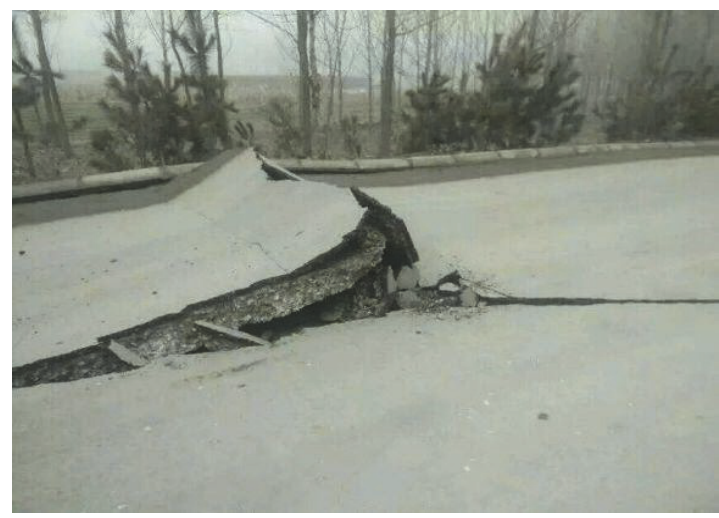

(a)

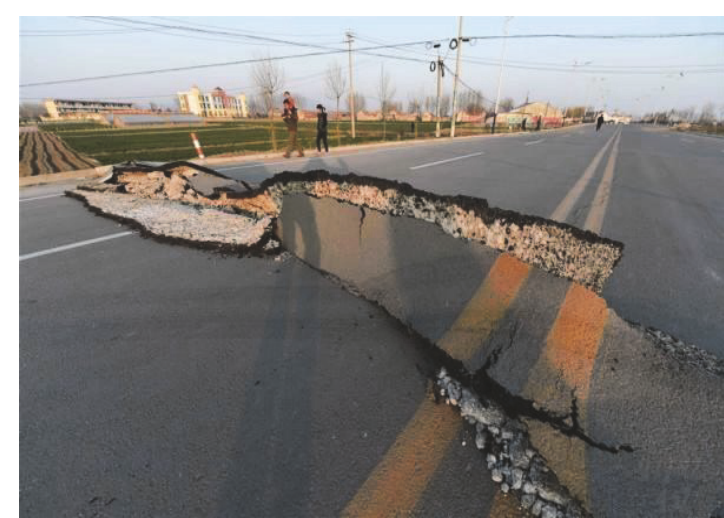

(b)

FIGURE 1: The damage of roads caused by the collapse of underground goafs in Shengda iron mine, where the vibration intensity was equal to an earthquake with the magnitude 3.1 .

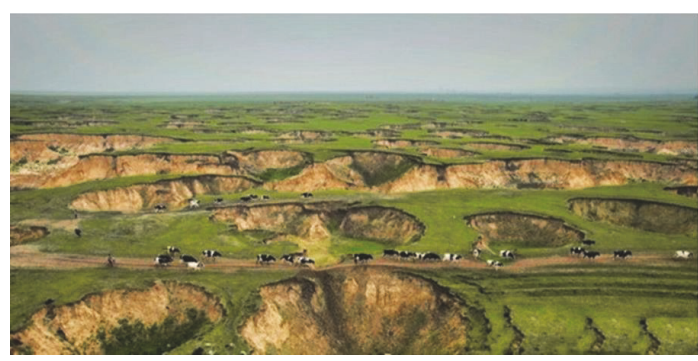

FIGURE 2: The huge and numerous collapse pits distributed in the Hulun Buir, where the vegetation, environment, and ecological system were damaged seriously.

distribution range of underground goafs is extremely large and the locations are strongly concealed, which threatens the safety of mine production and surrounding environment.

The statistical results show that more than 180 places with large area of ground subsidence have been found in 21 provinces of China, which have caused more than 1592 collapse pits and more than 200 deaths. Based on the analysis of these accidents, two significant aspects for the harm of underground goafs are summarized [18]. One aspect is the large area falling of underground goafs roofs, which results in the subsidence and cracking of surface, the destruction of mine environment, and heavy casualties. For example, a ground subsidence accident occurred at Shengda mine [19]. The nearby roads and buildings were damaged with different levels by an induced vibration, where the vibration intensity was equal to an earthquake with the magnitude 3.1 (Figure 1). In addition, a large number of collapse pits were found in Hulun Buir (Figure 2). The vegetation was damaged seriously due to the large-scale coal mining, which led to the environmental disruption and imbalance of the ecological system [20]. Another aspect is the groundwater inrush accident caused by numerous underground goafs and blasting vibration. Since, in the mining process, the rock fractures in the surrounding rock of underground goafs will develop due to the impact of blasting vibration and even connect to the surface or the chamber which contains water fully, thus the tunnels and working face will be inundated and causing huge losses. For example, a groundwater inrush accident occurred at Nandan, Guangxi Province, on 7 July 2001. In this disastrous accident, two mines were inundated at the same time and 81 people were killed. The volume of groundwater inrush was more than $34 \times 10^{4} \mathrm{~m}^{3}$ and the direct economic losses reached 80 million yuan [21].

Furthermore, the environmental engineering geological problems induced by underground goafs also have a serious impact on the mine production, transportation, pipeline, land, and water movement. It is typical to note that there are a total of 1982 locations with different degrees of ground subsidence in the Fankou lead-zinc mine, Guangdong Province. The area of ground subsidence has reached $675 \mathrm{~km}^{2}$ and the area of damaged farmland is about $66.7 \mathrm{~km}^{2}$. The area of the removed surrounding buildings is $7 \mathrm{~km}^{2}$. Besides, a national highway between Laizhou and Zhaoyuan suffered serious ground subsidence, which resulted in the destructions of traffic and surrounding buildings. At the same time, the adjacent underground goafs are more likely to penetrate each other and cause large-scale collapse of domino type [22]. Thus, the evaluation of underground goafs risk degrees is a significant and urgent problem.

Focusing on the problems of underground goafs, some remarkable methods including the accurate detection methods and stability analysis have been developed for underground goafs [23-28]. Measurement works include shear movements [29], water [30], and locations of underground goafs [31]. The stability analysis of underground goafs focused on mechanism and stability evaluation in the ground subsidence [26], numerical analysis [27], and prediction model for mining subsidence [28].

However, the evaluation of underground goaf risk degree is carried out through the single index in the existing methods, where the area of underground goafs is considered commonly [32]. The application of comprehensive evaluation method for underground goaf risk degree using multiple 
TABLE 1: Classification criteria for evaluation of risk levels with qualitative indexes.

\begin{tabular}{|c|c|c|c|c|}
\hline \multirow{2}{*}{ Evaluation indexes } & \multicolumn{4}{|c|}{ Classification } \\
\hline & Risk level $C_{1}$ & Risk level $C_{2}$ & Risk level $C_{3}$ & Risk level $C_{4}$ \\
\hline Rock mass structure $\left(X_{1}\right)$ & Complete structure & Stratified structure & Cracked structure & Loose structure \\
\hline Geological structure $\left(X_{2}\right)$ & $\begin{array}{l}\text { Without faults or } \\
\text { folds }\end{array}$ & $\begin{array}{c}\text { Impact of folds is } \\
\text { small }\end{array}$ & $\begin{array}{c}\text { Impact of folds is } \\
\text { huge }\end{array}$ & $\begin{array}{l}\text { The faults penetrate } \\
\text { surrounding rock }\end{array}$ \\
\hline Groundwater $\left(X_{4}\right)$ & $\begin{array}{c}\text { Without water } \\
\text { spraying }\end{array}$ & $\begin{array}{l}\text { Little water spraying } \\
\text { when rainfall exists }\end{array}$ & $\begin{array}{l}\text { Water spraying when } \\
\text { rainfall is huge }\end{array}$ & $\begin{array}{l}\text { Water spraying in } \\
\text { rainy season }\end{array}$ \\
\hline Impact of groundwater $\left(X_{5}\right)$ & $\begin{array}{l}\text { Without impact for } \\
\text { surrounding rock }\end{array}$ & $\begin{array}{c}\text { Little impact for } \\
\text { surrounding rock }\end{array}$ & $\begin{array}{l}\text { General impact for } \\
\text { surrounding rock }\end{array}$ & $\begin{array}{l}\text { Huge impact for } \\
\text { surrounding rock }\end{array}$ \\
\hline Mining impact $\left(X_{6}\right)$ & Little blasting impact & $\begin{array}{c}\text { General blasting } \\
\text { impact }\end{array}$ & Huge blasting impact & Great blasting impact \\
\hline $\begin{array}{l}\text { Condition of adjacent } \\
\text { underground goaf }\left(X_{7}\right)\end{array}$ & $\begin{array}{l}\text { No more } \\
\text { underground goafs in } \\
\text { the influencing area }\end{array}$ & $\begin{array}{l}\text { The area of } \\
\text { underground goafs is } \\
\text { medium and the } \\
\text { number is small }\end{array}$ & $\begin{array}{c}\text { The area of } \\
\text { underground goafs is } \\
\text { large and the number } \\
\text { is great, while the } \\
\text { distribution is } \\
\text { scattered }\end{array}$ & $\begin{array}{l}\text { The area of } \\
\text { underground goafs is } \\
\text { large, the number is } \\
\text { great, and the } \\
\text { distribution is } \\
\text { concentrated }\end{array}$ \\
\hline Pillar size and layout $\left(X_{11}\right)$ & $\begin{array}{l}\text { The pillar exists and } \\
\text { the layout is standard }\end{array}$ & $\begin{array}{c}\text { The pillar exists but } \\
\text { the layout is } \\
\text { nonstandard }\end{array}$ & $\begin{array}{c}\text { Without pillar or the } \\
\text { layout is nonstandard; } \\
\text { the pillar begins to be } \\
\text { damaged }\end{array}$ & $\begin{array}{c}\text { Without pillar or the } \\
\text { layout is nonstandard; } \\
\text { the pillar is damaged } \\
\text { seriously }\end{array}$ \\
\hline $\begin{array}{l}{ }^{1} \text { Size of underground goaf } \\
\left(X_{13}\right)\end{array}$ & $r<1$ & $1 \leq r<2$ & $2 \leq r<3$ & $r \geq 3$ \\
\hline Engineering layout $\left(X_{14}\right)$ & Reasonable & Generally reasonable & Partly reasonable & $\begin{array}{c}\text { Extremely } \\
\text { unreasonable }\end{array}$ \\
\hline
\end{tabular}

${ }^{1} r$ is the ratio of span to height.

indexes is scarce. As for the existing risk evaluation methods considering multiple evaluation indexes, most of them perform risk evaluation through the safety checklist, which is of qualitative evaluation. Actually, the weights of evaluation indexes will be affected seriously due to the subjective judgment, which leads to the inaccuracy and deviation of evaluation results. Recently, some comprehensive evaluation methods have been developed including grey fixed weight clustering method, grey relational analysis method, and neural network method [21, 33-35]. In fact, the difficulty for evaluating underground goaf risk degree lies in the uncertainties and concealments of the influencing factors, which should be considered and analyzed together. Thus, a comprehensive method for evaluating the underground goaf risk degree, as well as ranking the order, is necessary and important. According to the ranked order of underground goafs risk degrees, it is feasible to provide theoretical support for the management order of underground goafs with higher safety hazards. Then, the underground goafs with severe safety threats can be managed timely, to avoid casualties and environmental destruction.

In this paper, UME and AHP theories are applied to evaluate underground goafs risk degrees comprehensively [36-38]. The recognition criteria CDRC and TMMP are used to evaluate the risk levels of underground goafs. The multiple factors that influence the stability of underground goafs are considered and integrated comprehensively, which include the quantitative and qualitative factors, instead of a single factor. In addition, the quantitative and qualitative analysis are combined, and the qualitative factors are calculated with the quantitative form. According to the comparison and analysis of the 4 coupled methods formed through the combination of UME, AHP, CDRC, and TMMP, it is expected to develop a reasonable method for the evaluation of underground goaf risk degree, which is beneficial for the protection of environment and the sustained development of green mining.

\section{Materials and Methods}

2.1. The Index System for the Evaluation of Underground Goaf Risk Degree. The underground goafs are of irregular geometric shapes and complex spatial distributions, where numerous factors have effects on the risk degrees. Based on the analysis of factors that influence the stability of underground goafs, 9 factors are selected as the qualitative single evaluation indexes including rock mass structure, geological structure, groundwater, impact of groundwater, mining impact, condition of adjacent underground goaf, pillar size and layout, the size of underground goaf (the ratio of the span to the height), and engineering layout, which are represented with $X_{1}, X_{2}, X_{4}, X_{5}, X_{6}, X_{7}, X_{11}$, $X_{13}$, and $X_{14}$, respectively. In addition, 5 factors are selected as the quantitative single evaluation indexes including rock quality designation (RQD), span, area, height, and buried depth, which are represented with $X_{3}, X_{8}, X_{9}, X_{10}$, and $X_{12}$, respectively. Tables 1 and 2 show the classification criteria of the 9 qualitative indexes and the 5 quantitative indexes, 
TABLE 2: Classification criteria for evaluation of risk levels with quantitative indexes.

\begin{tabular}{lcccc}
\hline Evaluation indexes & & \multicolumn{3}{c}{ Classification } \\
& Risk level $C_{1}$ & Risk level $C_{2}$ & Risk level $C_{3}$ & ${\text { Risk level } C_{4}}$ \\
\hline RQD $\left(X_{3}\right) / \%$ & $>60$ & $50-60$ & $40-50$ & $<40$ \\
Span $\left(X_{8}\right) / \mathrm{m}$ & $<40$ & $40-80$ & $80-120$ & $>120$ \\
Area $\left(X_{9}\right) / \mathrm{m}^{2}$ & $<800$ & $800-1200$ & $1200-2400$ & $>2400$ \\
Height $\left(X_{10}\right) / \mathrm{m}$ & $<8$ & $8-20$ & $20-30$ & $>30$ \\
Buried depth $\left(X_{12}\right) / \mathrm{m}$ & $<100$ & $100-200$ & $200-400$ & $>400$ \\
\hline
\end{tabular}

respectively. In order to evaluate the risk degrees comprehensively and reasonably, the risk degrees are classified into 4 levels, which are $C_{1}, C_{2}, C_{3}$, and $C_{4}$. The risk levels $C_{1}, C_{2}, C_{3}$, and $C_{4}$ represent little dangerous, generally dangerous, very dangerous, and extremely dangerous, respectively. For the underground goafs with different risk levels, the management methods are listed as follows:

(i) For the underground goafs that belong to the risk level $C_{1}$, they should be monitored on schedule. The management process should be accomplished within twelve months.

(ii) For the underground goafs that belong to the risk level $\mathrm{C}_{2}$, they should be closed and separated. In addition, the distinct sign should be set up and the filling operation should be prepared in the meanwhile. The whole process should be accomplished within six months.

(iii) For the underground goafs that belong to the risk level $C_{3}$, the distinct sign should be set up. The filling operation should be carried out within three months.

(iv) For the underground goafs that belong to the risk level $C_{4}$, they should be closed and filled immediately. Moreover, the caving method should be applied as long as the safety requirements are satisfied. The whole process should be accomplished within one month.

2.2. Determination of the Single Index Measurement Value. The underground goaf to be evaluated is represented as the symbol $R$. The variable $X_{i}$ represents a single evaluation index. As the number of selected evaluation indexes is 14 , the evaluation index space is represented as $X=$ $\left\{X_{1}, X_{2}, \ldots, X_{14}\right\}$. For the underground goaf $R$ to be evaluated, $x_{i}$ is the measured value corresponding to the single evaluation index $X_{i}$. Therefore, the parameter $R$ can be represented as a vector $R=\left\{x_{1}, x_{2}, \ldots, x_{14}\right\}$. It is known that there are 4 risk levels for the underground goaf. The $k$ th risk level is represented as $C_{k}(k=1,2,3,4)$ and it is safer than the $(k+1)$ th risk level, which can be rewritten as $C_{k}<C_{k+1}$. The degree that the measured value $x_{i}$ belongs to the risk level $C_{k}$ is represented as $\mu_{i k}=\mu\left(x_{i} \in C_{k}\right)$. The parameter $\mu$ is exactly the single index measurement value, which is determined through the single index measurement function. Based on the analysis and comparison of different single index measurement functions, the semiridge distribution is selected to calculate the single index measurement values, which is shown as follows:

$$
\begin{aligned}
& \mu(x)= \begin{cases}0 & x \leq a \\
\frac{1}{2}+\frac{1}{2} \sin \frac{\pi}{b-a}\left(x-\frac{b+a}{2}\right) & a<x<b \\
1 & x \geq b\end{cases} \\
& \mu(x)= \begin{cases}1 & x \leq a \\
\frac{1}{2}-\frac{1}{2} \sin \frac{\pi}{b-a}\left(x-\frac{b+a}{2}\right) & a<x<b \\
0 & x \geq b,\end{cases}
\end{aligned}
$$

where $a$ and $b$ are the lower and upper limit of the value range. Equation (1) is the rising semiridge distribution for the quantitative positive indexes, where the risk levels of underground goafs increase with the increase of single evaluation index. Equation (2) is the descending semiridge distribution for the quantitative negative indexes, where the risk levels increase with the decrease of single evaluation index. The semiridge functions of the 9 qualitative evaluation indexes and 5 quantitative evaluation indexes are shown in Figure 3. Thus, it is feasible to solve the single index measurement values of 14 evaluation indexes. The evaluation matrix $\left(\mu_{i k}\right)_{14 \times 4}$ of single index measurement value is shown as follows:

$$
\left(\mu_{i k}\right)_{14 \times 4}=\left[\begin{array}{cccc}
\mu_{11} & \mu_{12} & \cdots & \mu_{14} \\
\mu_{21} & \mu_{22} & \cdots & \mu_{24} \\
\vdots & \vdots & \ddots & \vdots \\
\mu_{141} & \mu_{142} & \cdots & \mu_{144}
\end{array}\right]
$$

\subsection{The UME Theory}

2.3.1. Determination of Evaluation Index Weight. Based on the summary of UME theory proposed by Wang [37], we improve the theory to fit the evaluation of underground goafs risk degrees. It is assumed that $w_{i}$ is a parameter which represents the relatively important degree between the evaluation index $X_{i}$ and other indexes. The parameter $w_{i}$ can be taken as the weight of the evaluation index $X_{i}$, which should satisfy the requirements that $0 \leq w_{i} \leq 1$ and $\sum_{i=1}^{14} w_{i}=1$. 


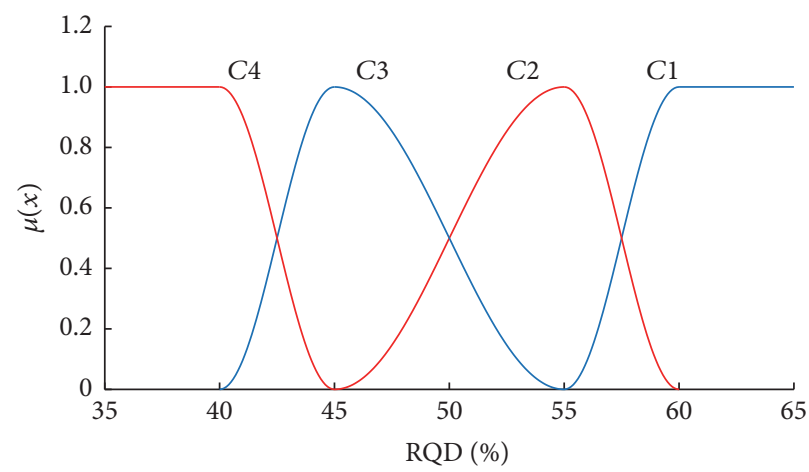

(a)

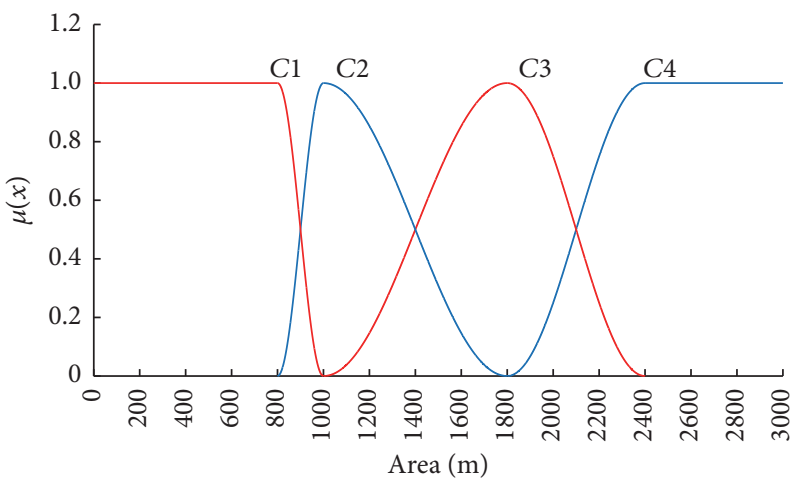

(c)

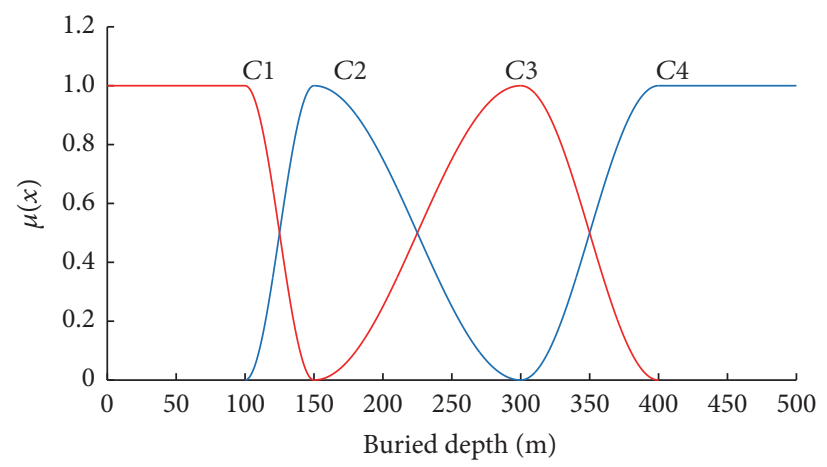

(e)

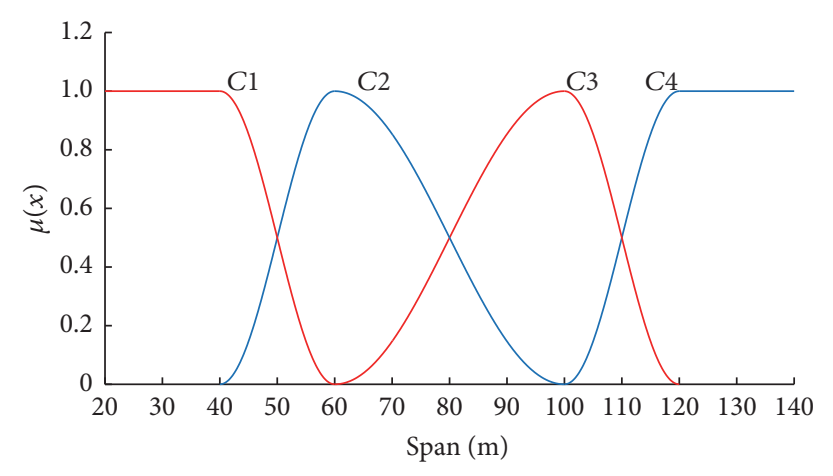

(b)

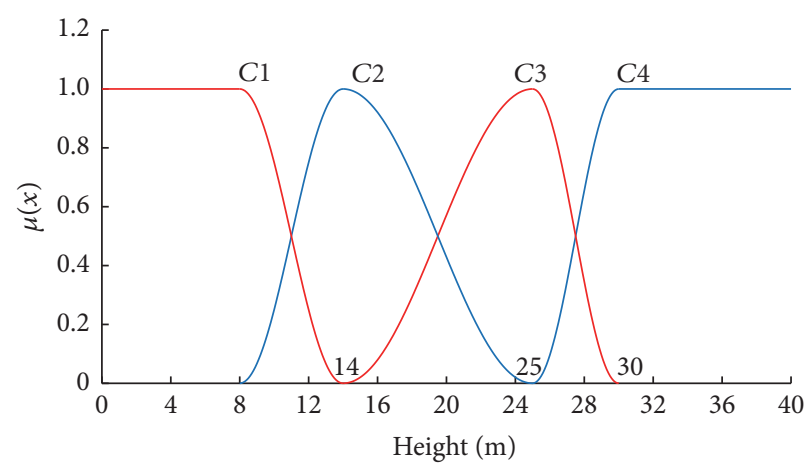

(d)

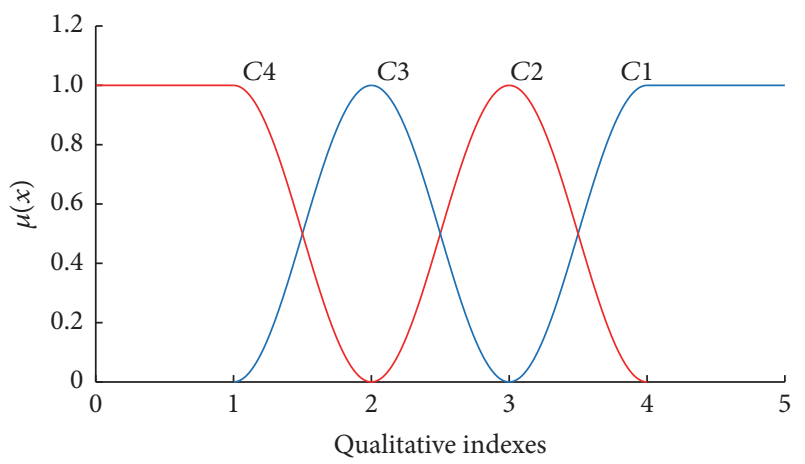

(f)

FIgURE 3: The single index measurement functions for evaluation indexes of underground goafs. The graphs (a), (b), (c), (d), and (e) show the functions of RQD, span, area, height, and buried depth, respectively. The graph (f) shows the function of rock mass structure, geological structure, groundwater, impact of groundwater, mining impact, condition of adjacent underground goaf, pillar size and layout, and engineering layout.

The weight $w_{i}$ can be determined by the entropy theory through the following equations:

$$
\begin{aligned}
& v_{i}=1+\frac{1}{\lg 4} \sum_{k=1}^{4} \mu_{i k} \lg \mu_{i k} \\
& w_{i}=\frac{v_{i}}{\sum_{i=1}^{14} v_{i}} .
\end{aligned}
$$

The evaluation matrix $\left(\mu_{i k}\right)_{14 \times 4}$ of single index measurement value is known, and the weight $w_{i}$ can be determined through (4).
2.3.2. The Comprehensive Evaluation Vector of Multiple Index Measurements. The degree of the underground goaf $R$ belongs to the risk level $C_{k}$, which is represented as $\gamma_{k}=$ $\gamma\left(R \in C_{k}\right)$. It can be obtained through

$$
\gamma_{k}=\sum_{i=1}^{14} w_{i} \mu_{i k} \quad(k=1,2,3,4) .
$$

It is obvious that the requirements $0 \leq \gamma_{k} \leq 1$ and $\sum_{k=1}^{4} \gamma_{k}=1$ are satisfied here. Therefore, $\left\{\gamma_{1}, \gamma_{2}, \gamma_{3}, \gamma_{4}\right\}$ is the comprehensive evaluation vector of multiple indexes measurements for the underground goaf $R$. 


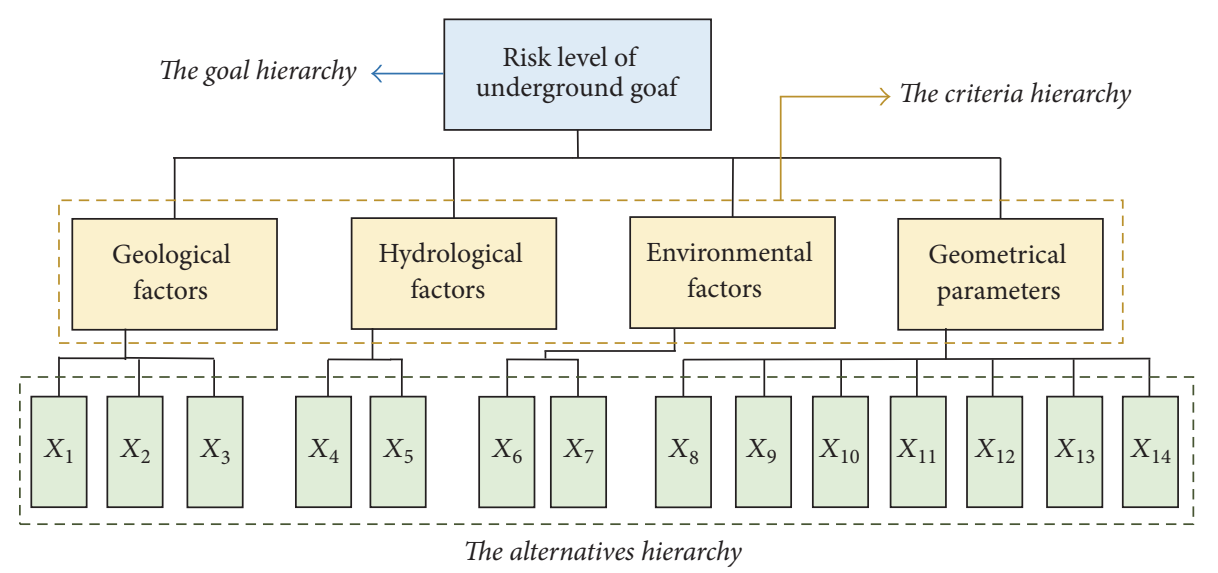

FIGURE 4: The hierarchical model for AHP, which consists of the goal hierarchy, the criteria hierarchy, and the alternatives hierarchy.

\subsection{The AHP Theory}

2.4.1. Establishment of a Hierarchical Model. According to the ideas and methods of AHP presented by Orencio and Fujii [36], the hierarchical model is established as shown in Figure 4, which consists of the goal hierarchy $G$, the criteria hierarchy $P$, and the alternatives hierarchy $X$. The problem to be solved is taken as the goal hierarchy $G$, which is the risk level $C_{k}$ of the underground goaf $R$ in this paper. The criteria hierarchy $P$ is determined based on the analysis of the practical problem and the relationships between single evaluation indexes, which consists of geological factors, hydrological factors, environmental factors, and geometrical parameters. Specifically, the geological factors contain $X_{1}$, $X_{2}$, and $X_{3}$. The hydrological factors contain $X_{4}$ and $X_{5}$. The environmental factors contain $X_{6}$ and $X_{7}$. The geometrical parameters contain $X_{8}, X_{9}, X_{10}, X_{11}, X_{12}, X_{13}$, and $X_{14}$. All the single evaluation indexes make up the alternatives hierarchy, which is the lowest hierarchy.

2.4.2. Determination of the Judgment Matrix. According to the importance degree for the 4 criteria in the middle hierarchy $P$, the relative importance degree can be determined by 1-9 comparison scale method, which is clarified as follows. The number 9 indicates the greatest importance degree, while the number 1 indicates the smallest importance degree. It is assumed that $P_{a b}(1 \leq a, b \leq 4)$ is the judgment value of the criterion $P_{a}$ with respect to the criterion $P_{b}$, which indicates the importance degree. On the contrary, $P_{b a}$ is the judgment value of the criterion $P_{b}$ with respect to the criterion $P_{a}$, which is equal to the reciprocal of $P_{a b}$. The detailed steps for determining $P_{a b}$ and $P_{b a}$ are shown in Table 3. Through (6), the judgment values can be solved by comparing $P_{a}$ and $P_{b}$. Therefore, the judgment matrix $G$ for the goal hierarchy can be obtained, which is shown as (7). Then, the greatest characteristic root and corresponding normalized feature vector of the judgment matrix $G$ can be solved. Similarly, the judgment matrixes, greatest characteristic roots, and corresponding normalized feature vectors of the criteria hierarchies $P_{1}, P_{2}, P_{3}$, and $P_{4}$ can be solved.
TABLE 3: The judgment values for determining the importance degree between the criteria $P_{a}$ and $P_{b}$.

\begin{tabular}{lcc}
\hline The importance degree for comparing $P_{a}$ and & $P_{a b}$ & $P_{b a}$ \\
$P_{b}$ & 1 & 1 \\
\hline$a$ and $b$ are "equally important" & 3 & $1 / 3$ \\
$a$ is "a little more important" than $b$ & 5 & $1 / 5$ \\
$a$ is "obviously important" compared to $b$ & 7 & $1 / 7$ \\
$a$ is "significantly more important" than $b$ & 9 & $1 / 9$ \\
$a$ is "extremely important" compared to $b$ & & $1 / P_{a b}$ \\
The importance degree of $P_{a}$ with respect to $P_{b}$ & $2,4,6,8$ & \\
is between the above levels & &
\end{tabular}

TABLE 4: The values for average random consistency index (RI).

\begin{tabular}{cccccccccccc}
\hline$T$ & 1 & 2 & 3 & 4 & 5 & 6 & 7 & 8 & 9 & 10 & 11 \\
\hline RI & 0 & 0 & 0.58 & 0.90 & 1.12 & 1.24 & 1.32 & 1.41 & 1.45 & 1.49 & 1.51 \\
\hline
\end{tabular}

$$
\begin{aligned}
g_{a b} & =\frac{P_{a}}{P_{b}}, \\
g_{b a} & =\frac{P_{b}}{P_{a}} \\
G_{4 \times 4} & =\left[\begin{array}{llll}
g_{11} & g_{12} & g_{13} & g_{14} \\
g_{21} & g_{22} & g_{23} & g_{24} \\
g_{31} & g_{32} & g_{33} & g_{34} \\
g_{41} & g_{42} & g_{43} & g_{44}
\end{array}\right] .
\end{aligned}
$$

2.4.3. The Consistency Check of the Judgment Matrix. The consistency check should be performed for the judgment matrixes to determine whether they are qualified. According to (8), the consistency index (CI) is solved. The average random consistency index (RI) can be found from Table 4 . 
Then, we can calculate the consistency ratio (CR) through (9), which is equal to the ratio of CI to RI. The consistency of the judgment matrix is qualified when there is $\mathrm{CR}<0.1$. Otherwise, the judgment matrix should be determined again with different criteria.

$$
\begin{aligned}
\mathrm{CI} & =\frac{\lambda_{\max }-t}{t-1} \\
\mathrm{CR} & =\frac{\mathrm{CI}}{\mathrm{RI}},
\end{aligned}
$$

where $t$ is the number of rows for the judgment matrix to be checked.

2.4.4. Determination of the Synthetic Weight. As the judgment matrixes, the greatest characteristic roots, and the corresponding feature vectors of $G, P_{1}, P_{2}, P_{3}$, and $P_{4}$ are known, the consistency check can be performed for these judgment matrixes. The results of the judgment matrixes, the greatest characteristic roots, and the corresponding feature vectors are shown in (10). The synthetic weights of all the evaluation indexes are represented as $W_{i}$, which are shown in Table 5.

$$
\begin{aligned}
& G=\left[\begin{array}{llll}
1.0000 & 1.8000 & 1.2857 & 0.8889 \\
0.5556 & 1.0000 & 0.6667 & 0.4444 \\
0.7778 & 1.5000 & 1.0000 & 0.6667 \\
1.1250 & 2.2500 & 1.5000 & 1.0000
\end{array}\right], \quad \sigma_{G}=(0.2873,0.1528,0.2252,0.3348)^{T}, \lambda_{\max }=4.0011, \mathrm{CR}<0.10 \\
& P_{1}=\left[\begin{array}{lll}
1.0000 & 0.6667 & 0.8889 \\
1.5000 & 1.0000 & 1.2857 \\
1.1250 & 0.7778 & 1.0000
\end{array}\right], \quad \sigma_{P_{1}}=(0.2762,0.4093,0.3145)^{T}, \quad \lambda_{\max }=3.0002, \quad \mathrm{CR}<0.10 \\
& P_{2}=\left[\begin{array}{ll}
1.0000 & 0.6667 \\
1.5000 & 1.0000
\end{array}\right], \quad \sigma_{P_{2}}=(0.4000,0.6000)^{T}, \quad \lambda_{\max }=2.0000, \quad \mathrm{CR}<0.10 \\
& P_{3}=\left[\begin{array}{ll}
1.0000 & 1.5000 \\
0.6667 & 1.0000
\end{array}\right], \quad \sigma_{P_{3}}=(0.6000,0.4000)^{T}, \quad \lambda_{\max }=2.0000, \quad \mathrm{CR}<0.10 \\
& P_{4}=\left[\begin{array}{lllllll}
1.0000 & 1.1250 & 1.2857 & 1.1250 & 1.5000 & 1.5000 & 1.5000 \\
0.8889 & 1.0000 & 1.1250 & 1.0000 & 1.2857 & 1.2857 & 1.2857 \\
0.7778 & 0.8889 & 1.0000 & 0.8889 & 1.1250 & 1.1250 & 1.1250 \\
0.8889 & 1.0000 & 1.1250 & 1.0000 & 1.2857 & 1.2857 & 1.2857 \\
0.6667 & 0.7778 & 0.8889 & 0.7778 & 1.0000 & 1.0000 & 1.0000 \\
0.6667 & 0.7778 & 0.8889 & 0.7778 & 1.0000 & 1.0000 & 1.0000 \\
0.6667 & 0.7778 & 0.8889 & 0.7778 & 1.0000 & 1.0000 & 1.0000
\end{array}\right] \text {, }
\end{aligned}
$$$$
\sigma_{P_{4}}=(0.1803,0.1574,0.1387,0.1574,0.1221,0.1221,0.1221)^{T}, \lambda_{\max }=7.0003, \mathrm{CR}<0.10 .
$$

2.4.5. Determination of the Evaluation Vector. The degree that the underground goaf $R$ belongs to the risk level $C_{k}$ is represented as $\eta$. Since the evaluation matrix $\left(\mu_{i k}\right)_{14 \times 4}$ of single index measurement value and the weights of hierarchical model are known, the comprehensive evaluation vector $\left\{\eta_{1}, \eta_{2}, \eta_{3}, \eta_{4}\right\}$ can be obtained by multiplying the weights and evaluation matrix from the alternatives hierarchy to the goal hierarchy.

2.5. The Recognition Criteria for UME and AHP. In order to make sure that the evaluation results for underground goafs are reasonable and reliable, CDRC and TMMP are applied to compare the evaluation results and verify the reasonability.
2.5.1. The Credible Degree Recognition Criterion (CDRC). The credible degree is represented as $\xi(\xi \geq 0.5)$. It is credible that the underground goaf $R$ belongs to the evaluation level $C_{k}$ when the following requirements are satisfied:

$$
\begin{aligned}
C_{1}<C_{2}<C_{3}<C_{4} \\
k=\min \left\{k: \sum_{j=1}^{k} \mu_{j} \geq \xi,(k=1,2,3,4)\right\} .
\end{aligned}
$$

2.5.2. The Maximum Membership Principle (TMMP). The membership for the evaluation level $C_{k}$ of the underground goaf $R$ is exactly the corresponding weight. In UME method, it is equal to $\gamma_{k}$, whereas it is equal to $\eta_{k}$ in the AHP method. 
TABLE 5: The results of the weights in the hierarchical model.

\begin{tabular}{|c|c|c|c|}
\hline $\begin{array}{l}\text { Weight of the goal } \\
\text { hierarchy }(G)\end{array}$ & Weights of the criteria hierarchy $(P)$ & Weights of the alternatives hierarchy $(X)$ & The synthetic weights $(W)$ \\
\hline \multirow{14}{*}{$\begin{array}{l}\text { The risk level } C_{k} \text {, the } \\
\text { underground goaf } R\end{array}$} & \multirow{3}{*}{$P_{1}$-geological factors $(0.2873)$} & $X_{1}(0.2762)$ & 0.0793 \\
\hline & & $X_{2}(0.4093)$ & 0.1176 \\
\hline & & $X_{3}(0.3145)$ & 0.0903 \\
\hline & \multirow{2}{*}{$P_{2}$-hydrological factors $(0.1528)$} & $X_{4}(0.4000)$ & 0.0611 \\
\hline & & $X_{5}(0.6000)$ & 0.0917 \\
\hline & \multirow{2}{*}{$P_{3}$-environmental factors $(0.2252)$} & $X_{6}(0.6000)$ & 0.1351 \\
\hline & & $X_{7}(0.4000)$ & 0.0901 \\
\hline & \multirow{7}{*}{$P_{4}$-geometrical parameters $(0.3348)$} & $X_{8}(0.1803)$ & 0.0604 \\
\hline & & $X_{9}(0.1574)$ & 0.0527 \\
\hline & & $X_{10}(0.1387)$ & 0.0464 \\
\hline & & $X_{11}(0.1574)$ & 0.0527 \\
\hline & & $X_{12}(0.1221)$ & 0.0409 \\
\hline & & $X_{13}(0.1221)$ & 0.0409 \\
\hline & & $X_{14}(0.1221)$ & 0.0409 \\
\hline
\end{tabular}

It is credible that the underground goaf $R$ belongs to the evaluation level $C_{k}$ when the corresponding weight is the maximum among all the weights.

2.6. The Method for Ranking the Order of Underground Goafs. There is not only a need to evaluate the risk level $C_{k}$ of the underground goaf $R$, but also a requirement to rank the order for many underground goafs according to the risk degrees. If there is $C_{1}<C_{2}<C_{3}<C_{4}$ and $I_{k}$ is the score value of $C_{k}$, then we can obtain the following equations:

$$
\begin{gathered}
I_{k}<I_{k+1} \\
q_{R}=\sum_{k=1}^{4} I_{k} \mu_{k},
\end{gathered}
$$

where $q_{R}$ is the uncertainty important degree of the underground goaf $R$. Therefore, the order for risk degrees of many underground goafs can be ranked by the values of $q_{R}$.

2.7. The Evaluation Process for Risk Levels of Underground Goafs. Firstly, the single index measurement value can be solved based on the semiridge distribution. Then, we can obtain the evaluation matrix $\left(\mu_{i k}\right)_{14 \times 4}$ of single index measurement value. Secondly, the weights of single evaluation indexes in UME can be solved through the entropy theory. In the AHP theory, all the weights can be solved through the AHP. Then, it is feasible to obtain the comprehensive evaluation vectors of UME and AHP. Finally, the recognition criteria including CDRC and TMMP are applied to evaluate the risk level of the underground goaf. Therefore, there are 4 coupled evaluation methods for the risk level through the combination of UME, AHP, CDRC, and TMMP. The comprehensive evaluation process for the risk level $C_{k}$ of the underground goaf $R$, which mainly includes UME-CDRC, UME-TMMP, AHP-CDRC, and AHP-TMMP, is shown in Figure 5.

\section{Results}

3.1. The Dabaoshan Mine. The Dabaoshan mine is located in Guangdong Province, China, where there is a superimposition place of one fault belt and another tectonic belt. Due to the open stope mining and illegal mining, numerous underground goafs formed and caused the continuous increase of geostress. Figures 6(a) and 6(b) show the distinct geostatic activities such as pillar cracking and roof falling, which threaten the safety of ground, slope, and underground production system. In the mining process, the sizes of some underground goafs were large, while the sizes of pillars were too small to bear the pressure. Then, the pillar cracking and the large area falling caused a serious landslide accident, which caused threat and destruction to workers and environment. Figure 6(c) shows the landslide accident caused by the collapse of underground goafs.

The statistical results of Dabaoshan mine show that the number of underground goafs is 254 , and most geometric shapes are irregular. The volume of the smaller underground goaf is about $400 \mathrm{~m}^{3}$, whereas the larger volume is greater than $10 \times 10^{4} \mathrm{~m}^{3}$ and the height is greater than $100 \mathrm{~m}$. In view of the current status, the evaluation of underground goafs risk degrees is important and urgent.

Combined with the hydrogeologic conditions, environmental factors, mining status, and structural parameters of underground goafs, a total of 37 underground goafs are selected to evaluate the risk levels. The data for 14 single evaluation indexes of 37 underground goafs are listed in Table 6 [39]. According to the estimated and measured data provided in Table 6 , as well as the single index measurement values solved in Figure 3, the evaluation matrixes $\left(\mu_{i k}\right)_{14 \times 4}$ of single index measurement value for the 37 underground goafs can be obtained. The underground goaf $R_{1}$ is taken as an example to calculate the evaluation matrix $\left(\mu_{i k}\right)_{14 \times 4}$ of single index measurement value, which is shown as follows: 


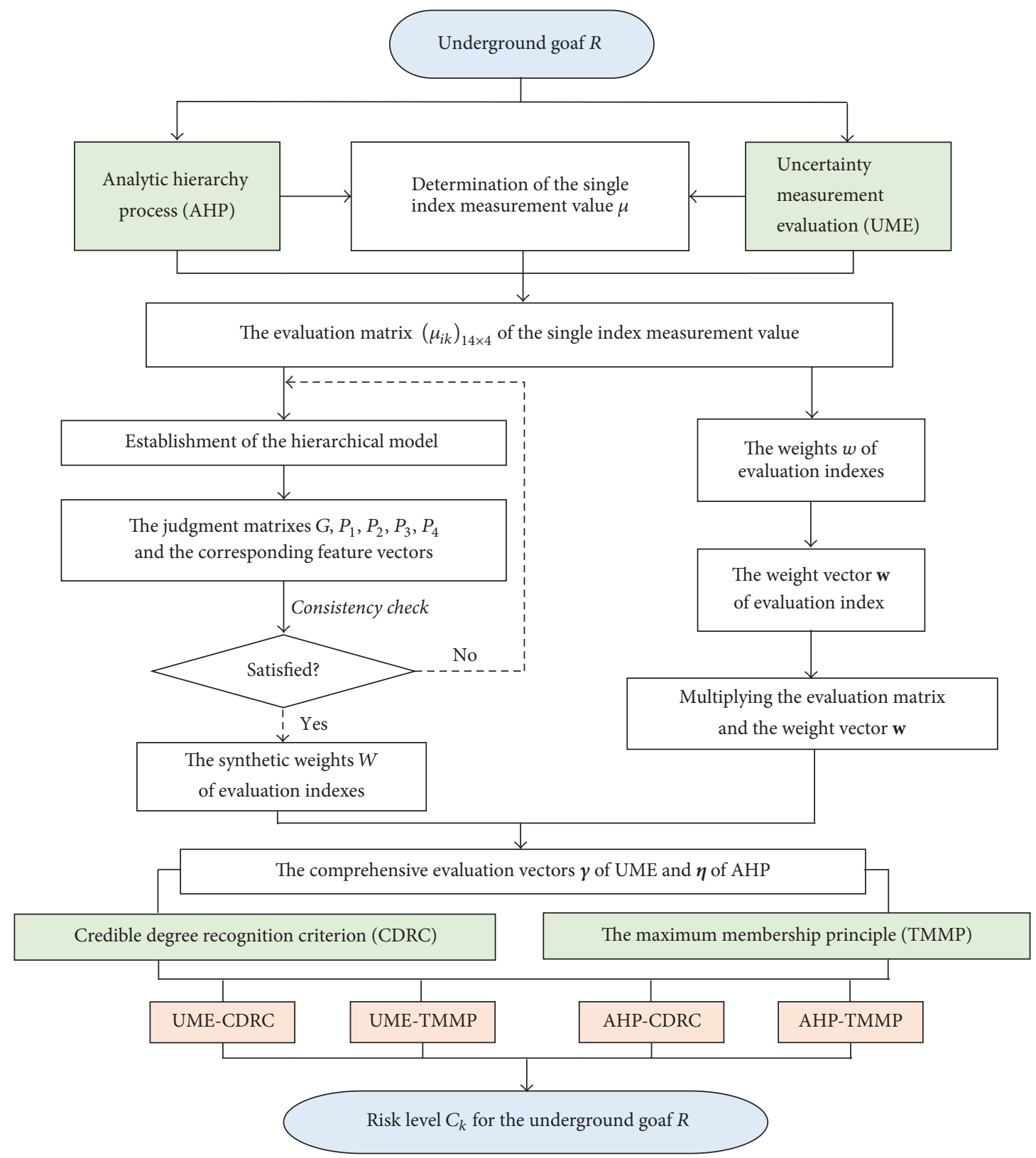

FiguRE 5: The flowchart for evaluating the risk level $C_{k}$ of the underground goaf $R$ comprehensively, where 4 coupled methods including UME-CDRC, UME-TMMP, AHP-CDRC, and AHP-TMMP are applied.

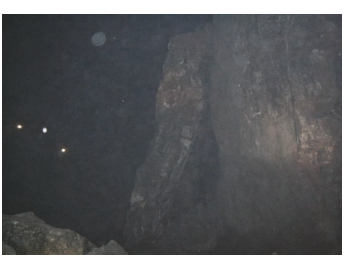

(a)

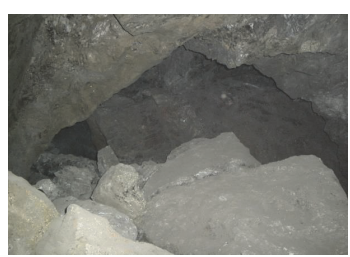

(b)

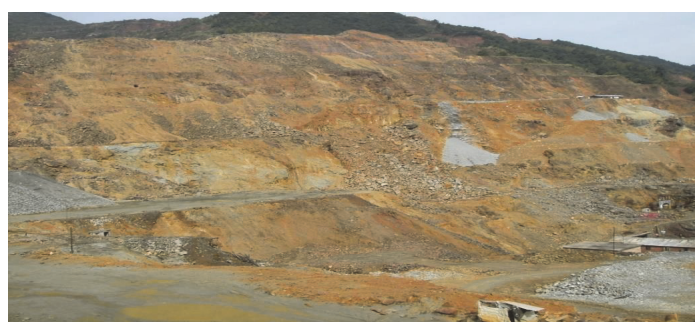

(c)

FIGURE 6: The distinct geostatic activities and scene of accident of Dabaoshan mine. (a) shows the pillar cracking phenomenon, (b) shows the large-scale falling in a underground goaf, and (c) shows the landslide accident caused by the collapse of underground goafs. 
TABLE 6: Estimated and measured data for single evaluation indexes of 37 underground goafs.

\begin{tabular}{|c|c|c|c|c|c|c|c|c|c|c|c|c|c|c|}
\hline \multirow{2}{*}{ Number } & \multicolumn{14}{|c|}{ The risk evaluation indexes of underground goaf } \\
\hline & $X_{1}$ & $X_{2}$ & $X_{3} / \%$ & $X_{4}$ & $X_{5}$ & $X_{6}$ & $X_{7}$ & $X_{8} / \mathrm{m}$ & $X_{9} / \mathrm{m}^{2}$ & $X_{10} / \mathrm{m}$ & $X_{11}$ & $X_{12} / \mathrm{m}$ & $X_{13}$ & $X_{14}$ \\
\hline$R_{1}$ & 2 & 4 & 38 & 3 & 3 & 1 & 1 & 85 & 5190 & 15 & 1 & 260 & 3 & 3 \\
\hline$R_{2}$ & 3 & 3 & 56 & 3 & 3 & 1 & 1 & 60 & 1230 & 8 & 2 & 260 & 3 & 4 \\
\hline$R_{3}$ & 2 & 2 & 35 & 3 & 3 & 1 & 1 & 62 & 2560 & 14.5 & 1 & 290 & 2 & 3 \\
\hline$R_{4}$ & 2 & 3 & 48 & 3 & 3 & 1 & 1 & 73 & 1740 & 22 & 1 & 280 & 1 & 2 \\
\hline$R_{5}$ & 2 & 3 & 43 & 3 & 3 & 1 & 1 & 60 & 1920 & 16.5 & 1 & 280 & 2 & 3 \\
\hline$R_{6}$ & 2 & 2 & 47 & 3 & 3 & 1 & 1 & 160 & 6890 & 26.3 & 1 & 305 & 1 & 2 \\
\hline$R_{7}$ & 3 & 4 & 55 & 4 & 4 & 4 & 4 & 26 & 2870 & 15.8 & 3 & 305 & 4 & 4 \\
\hline$R_{8}$ & 3 & 4 & 57 & 3 & 3 & 1 & 1 & 96 & 2260 & 21 & 2 & 335 & 3 & 4 \\
\hline$R_{9}$ & 4 & 4 & 67 & 3 & 3 & 4 & 4 & 60 & 1200 & 10 & 4 & 335 & 4 & 4 \\
\hline$R_{10}$ & 4 & 3 & 53 & 2 & 2 & 1 & 1 & 85 & 3970 & 60 & 1 & 240 & 3 & 3 \\
\hline$R_{11}$ & 4 & 3 & 59 & 4 & 4 & 4 & 4 & 40 & 2260 & 15 & 4 & 305 & 3 & 4 \\
\hline$R_{12}$ & 4 & 4 & 62 & 3 & 3 & 4 & 4 & 35 & 1450 & 13 & 4 & 290 & 4 & 4 \\
\hline$R_{13}$ & 4 & 4 & 52 & 3 & 3 & 2 & 2 & 35 & 2590 & 6 & 4 & 201 & 4 & 4 \\
\hline$R_{14}$ & 4 & 4 & 55 & 4 & 4 & 2 & 2 & 65 & 2430 & 12 & 4 & 208 & 4 & 4 \\
\hline$R_{15}$ & 2 & 2 & 56 & 3 & 3 & 2 & 2 & 83 & 2350 & 4.5 & 2 & 208 & 4 & 3 \\
\hline$R_{16}$ & 4 & 4 & 54 & 4 & 4 & 2 & 2 & 68 & 1800 & 10 & 4 & 208 & 3 & 4 \\
\hline$R_{17}$ & 4 & 3 & 57 & 3 & 3 & 1 & 1 & 55 & 1600 & 16 & 3 & 411 & 2 & 3 \\
\hline$R_{18}$ & 4 & 4 & 54 & 3 & 3 & 4 & 4 & 74 & 2000 & 8 & 2 & 300 & 3 & 4 \\
\hline$R_{19}$ & 4 & 4 & 55 & 4 & 4 & 2 & 2 & 59 & 1950 & 23 & 3 & 201 & 3 & 4 \\
\hline$R_{20}$ & 4 & 4 & 52 & 4 & 4 & 2 & 2 & 110 & 5000 & 7.5 & 4 & 195 & 4 & 4 \\
\hline$R_{21}$ & 4 & 4 & 51 & 4 & 4 & 2 & 2 & 85 & 3270 & 13 & 3 & 180 & 3 & 4 \\
\hline$R_{22}$ & 4 & 3 & 54 & 4 & 4 & 1 & 2 & 65 & 1300 & 7.5 & 2 & 180 & 3 & 3 \\
\hline$R_{23}$ & 4 & 3 & 55 & 4 & 4 & 1 & 1 & 73 & 1730 & 6.2 & 2 & 180 & 3 & 4 \\
\hline$R_{24}$ & 4 & 4 & 53 & 4 & 4 & 2 & 2 & 74 & 1870 & 6 & 4 & 230 & 4 & 4 \\
\hline$R_{25}$ & 4 & 4 & 53 & 4 & 4 & 2 & 2 & 68 & 1170 & 14 & 4 & 230 & 3 & 4 \\
\hline$R_{26}$ & 4 & 4 & 54 & 4 & 4 & 4 & 4 & 65 & 2490 & 16 & 4 & 230 & 3 & 4 \\
\hline$R_{27}$ & 4 & 4 & 53 & 4 & 4 & 4 & 4 & 78 & 2440 & 13 & 4 & 230 & 3 & 4 \\
\hline$R_{28}$ & 4 & 4 & 43 & 3 & 3 & 1 & 1 & 80 & 3480 & 23 & 1 & 230 & 2 & 2 \\
\hline$R_{29}$ & 4 & 4 & 55 & 4 & 4 & 4 & 4 & 85 & 1410 & 8 & 3 & 230 & 3 & 4 \\
\hline$R_{30}$ & 3 & 4 & 44 & 2 & 2 & 2 & 2 & 65 & 1750 & 85 & 1 & 350 & 2 & 3 \\
\hline$R_{31}$ & 4 & 4 & 52 & 4 & 4 & 4 & 4 & 70 & 1210 & 10 & 4 & 350 & 4 & 3 \\
\hline$R_{32}$ & 4 & 4 & 56 & 4 & 4 & 2 & 2 & 65 & 1320 & 13 & 1 & 375 & 3 & 3 \\
\hline$R_{33}$ & 4 & 4 & 57 & 4 & 4 & 2 & 2 & 65 & 3690 & 7.5 & 3 & 210 & 3 & 4 \\
\hline$R_{34}$ & 3 & 3 & 41 & 2 & 2 & 2 & 2 & 48 & 1420 & 18 & 2 & 210 & 2 & 2 \\
\hline$R_{35}$ & 4 & 3 & 40 & 2 & 2 & 1 & 2 & 62 & 1680 & 26 & 1 & 290 & 2 & 3 \\
\hline$R_{36}$ & 3 & 3 & 43 & 1 & 1 & 1 & 1 & 89 & 1290 & 63 & 1 & 290 & 2 & 3 \\
\hline$R_{37}$ & 4 & 3 & 42 & 3 & 3 & 1 & 1 & 120 & 4580 & 28 & 1 & 400 & 2 & 3 \\
\hline
\end{tabular}

$$
\left(\mu_{R_{1}}\right)_{14 \times 4}=\left[\begin{array}{cccc}
0 & 0 & 1.0000 & 0 \\
1.0000 & 0 & 0 & 0 \\
0 & 0 & 0 & 1.0000 \\
0 & 1.0000 & 0 & 0 \\
0 & 1.0000 & 0 & 0 \\
0 & 0 & 0 & 1.0000 \\
0 & 0 & 0 & 1.0000 \\
0 & 0.3087 & 0.6913 & 0 \\
0 & 0 & 0 & 1.0000 \\
0 & 0.9797 & 0.0203 & 0 \\
0 & 0 & 0 & 1.0000 \\
0 & 0.1654 & 0.8346 & 0 \\
0 & 1.0000 & 0 & 0 \\
0 & 1.0000 & 0 & 0
\end{array}\right] .
$$

3.2. The Results for Evaluation of Risk Levels. The underground goaf $R_{1}$ is taken as an example. According to UME theory, the weights of 14 single evaluation indexes can be obtained through the entropy theory, which are $w_{1}=0.0760$, $w_{2}=0.0760, w_{3}=0.0760, w_{4}=0.0760, w_{5}=0.0760$, $w_{6}=0.0760, w_{7}=0.0760, w_{8}=0.0421, w_{9}=0.0760, w_{10}=$ $0.0706, w_{11}=0.0760, w_{12}=0.0514, w_{13}=0.0760$, and $w_{14}=$ 0.0760 , respectively. Therefore, the comprehensive evaluation vector can be solved as $\gamma_{1}=\{0.0760,0.3946,0.1494,0.3800\}$. Based on the recognition criterion CDRC, it can be obtained that $k=0.0760+0.3946+0.1494=0.6200>\xi=0.5$ when the credible degree $\xi$ is set as 0.5 . Thus, the risk level of the underground goaf $R_{1}$ is level $C_{3}$. The risk level is evaluated as level $C_{2}$ while applying the recognition criterion TMMP.

According to the AHP theory, the weights of the criteria hierarchy and the alternatives hierarchy, as well as the 
TABLE 7: The comparison results for UME and AHP of 37 underground goafs, as well as the risk levels evaluated by CDRC and TMMP.

\begin{tabular}{|c|c|c|c|c|c|c|c|c|c|c|}
\hline \multirow{2}{*}{ Number } & \multicolumn{5}{|c|}{ UME-CDRC, UME-TMMP } & \multicolumn{5}{|c|}{ AHP-CDRC, AHP-TMMP } \\
\hline & $C_{1}$ & $C_{2}$ & $C_{3}$ & $C_{4}$ & (CDRC, TMMP) & $C_{1}$ & $\mathrm{C}_{2}$ & $C_{3}$ & $C_{4}$ & (CDRC, TMMP) \\
\hline$R_{1}$ & 0.0760 & 0.3946 & 0.1494 & 0.3800 & $(3,2)$ & 0.1176 & 0.3054 & 0.1561 & 0.4209 & $(3,4)$ \\
\hline$R_{2}$ & 0.1583 & 0.4837 & 0.1289 & 0.2290 & $(2,2)$ & 0.1726 & 0.4260 & 0.1235 & 0.2779 & $(2,2)$ \\
\hline$R_{3}$ & 0.0000 & 0.3601 & 0.2915 & 0.3485 & $(3,2)$ & 0.0000 & 0.3003 & 0.2819 & 0.4178 & $(3,4)$ \\
\hline$R_{4}$ & 0.0000 & 0.3967 & 0.2795 & 0.3238 & $(3,2)$ & 0.0000 & 0.3585 & 0.3228 & 0.3187 & $(3,2)$ \\
\hline$R_{5}$ & 0.0000 & 0.4366 & 0.3157 & 0.2477 & $(3,2)$ & 0.0000 & 0.4141 & 0.2745 & 0.3114 & $(3,2)$ \\
\hline$R_{6}$ & 0.0000 & 0.1544 & 0.3188 & 0.5268 & $(4,4)$ & 0.0000 & 0.1614 & 0.3588 & 0.4797 & $(3,4)$ \\
\hline$R_{7}$ & 0.5797 & 0.2735 & 0.0043 & 0.1425 & $(1,1)$ & 0.6376 & 0.2658 & 0.0033 & 0.0933 & $(1,1)$ \\
\hline$R_{8}$ & 0.1807 & 0.3752 & 0.2227 & 0.2215 & $(2,2)$ & 0.1897 & 0.3472 & 0.1810 & 0.2822 & $(2,2)$ \\
\hline$R_{9}$ & 0.6562 & 0.2910 & 0.0202 & 0.0326 & $(1,1)$ & 0.6817 & 0.2697 & 0.0189 & 0.0297 & $(1,1)$ \\
\hline$R_{10}$ & 0.0777 & 0.3153 & 0.2182 & 0.3887 & $(3,4)$ & 0.0793 & 0.3138 & 0.2299 & 0.3770 & $(3,4)$ \\
\hline$R_{11}$ & 0.6603 & 0.2265 & 0.0202 & 0.0930 & $(1,1)$ & 0.6930 & 0.2125 & 0.0266 & 0.0679 & $(1,1)$ \\
\hline$R_{12}$ & 0.6812 & 0.2245 & 0.0943 & 0.0000 & $(1,1)$ & 0.7103 & 0.2178 & 0.0719 & 0.0000 & $(1,1)$ \\
\hline$R_{13}$ & 0.5340 & 0.2241 & 0.1766 & 0.0652 & $(1,1)$ & 0.4381 & 0.2548 & 0.2563 & 0.0508 & $(2,1)$ \\
\hline$R_{14}$ & 0.5649 & 0.2104 & 0.1850 & 0.0397 & $(1,1)$ & 0.4957 & 0.2108 & 0.2517 & 0.0418 & $(2,1)$ \\
\hline$R_{15}$ & 0.1675 & 0.3445 & 0.4585 & 0.0294 & $(2,3)$ & 0.0959 & 0.3261 & 0.5427 & 0.0354 & $(3,3)$ \\
\hline$R_{16}$ & 0.5024 & 0.2424 & 0.2552 & 0.0000 & $(1,1)$ & 0.4781 & 0.2227 & 0.2992 & 0.0000 & $(2,1)$ \\
\hline$R_{17}$ & 0.1011 & 0.5329 & 0.1304 & 0.2356 & $(2,2)$ & 0.1194 & 0.5250 & 0.0895 & 0.2661 & $(2,2)$ \\
\hline$R_{18}$ & 0.4534 & 0.3260 & 0.2141 & 0.0065 & $(2,1)$ & 0.5094 & 0.3257 & 0.1588 & 0.0062 & $(1,1)$ \\
\hline$R_{19}$ & 0.3682 & 0.2964 & 0.3313 & 0.0041 & $(2,1)$ & 0.3910 & 0.2476 & 0.3580 & 0.0035 & $(2,1)$ \\
\hline$R_{20}$ & 0.6267 & 0.0787 & 0.1967 & 0.0979 & $(1,1)$ & 0.5306 & 0.1042 & 0.2824 & 0.0829 & $(1,1)$ \\
\hline$R_{21}$ & 0.3985 & 0.3144 & 0.2083 & 0.0788 & $(2,1)$ & 0.3937 & 0.2516 & 0.3020 & 0.0527 & $(2,1)$ \\
\hline$R_{22}$ & 0.3047 & 0.4438 & 0.1753 & 0.0762 & $(2,2)$ & 0.2786 & 0.4189 & 0.1675 & 0.1351 & $(2,2)$ \\
\hline$R_{23}$ & 0.3757 & 0.3138 & 0.1603 & 0.1503 & $(2,1)$ & 0.3194 & 0.3327 & 0.1227 & 0.2252 & $(2,2)$ \\
\hline$R_{24}$ & 0.6251 & 0.1050 & 0.2688 & 0.0011 & $(1,1)$ & 0.5306 & 0.1439 & 0.3248 & 0.0008 & $(1,1)$ \\
\hline$R_{25}$ & 0.4686 & 0.3356 & 0.1958 & 0.0000 & $(2,1)$ & 0.4433 & 0.2889 & 0.2678 & 0.0000 & $(2,1)$ \\
\hline$R_{26}$ & 0.6237 & 0.2889 & 0.0383 & 0.0492 & $(1,1)$ & 0.6685 & 0.2481 & 0.0375 & 0.0459 & $(1,1)$ \\
\hline$R_{27}$ & 0.6573 & 0.2437 & 0.0564 & 0.0426 & $(1,1)$ & 0.6716 & 0.2191 & 0.0668 & 0.0426 & $(1,1)$ \\
\hline$R_{28}$ & 0.1621 & 0.2058 & 0.2930 & 0.3392 & $(3,4)$ & 0.1969 & 0.2050 & 0.2363 & 0.3618 & $(3,4)$ \\
\hline$R_{29}$ & 0.6370 & 0.2896 & 0.0734 & 0.0000 & $(1,1)$ & 0.6622 & 0.2461 & 0.0917 & 0.0000 & $(1,1)$ \\
\hline$R_{30}$ & 0.0762 & 0.2370 & 0.5287 & 0.1581 & $(3,3)$ & 0.1176 & 0.1992 & 0.5755 & 0.1077 & $(3,3)$ \\
\hline$R_{31}$ & 0.6975 & 0.2536 & 0.0489 & 0.0000 & $(1,1)$ & 0.7033 & 0.2404 & 0.0564 & 0.0000 & $(1,1)$ \\
\hline$R_{32}$ & 0.3248 & 0.3670 & 0.2215 & 0.0867 & $(2,2)$ & 0.3614 & 0.2993 & 0.2806 & 0.0587 & $(2,1)$ \\
\hline$R_{33}$ & 0.4775 & 0.2741 & 0.1713 & 0.0772 & $(2,1)$ & 0.4682 & 0.2375 & 0.2416 & 0.0527 & $(2,1)$ \\
\hline$R_{34}$ & 0.0294 & 0.2658 & 0.6461 & 0.0587 & $(3,3)$ & 0.0395 & 0.3016 & 0.5771 & 0.0817 & $(3,3)$ \\
\hline$R_{35}$ & 0.0738 & 0.2231 & 0.4762 & 0.2269 & $(3,3)$ & 0.0793 & 0.2217 & 0.4163 & 0.2826 & $(3,3)$ \\
\hline$R_{36}$ & 0.0000 & 0.2773 & 0.2365 & 0.4862 & $(3,4)$ & 0.0000 & 0.2862 & 0.2055 & 0.5083 & $(4,4)$ \\
\hline$R_{37}$ & 0.0000 & 0.3060 & 0.1048 & 0.5892 & $(4,4)$ & 0.0000 & 0.3112 & 0.0843 & 0.6044 & $(4,4)$ \\
\hline
\end{tabular}

synthetic weights, are solved in Table 5. Combined with the evaluation matrix $\left(\mu_{i k}\right)_{14 \times 4}$ of single index measurement value, we can obtain the evaluation vector $\eta_{1}=$ $\{0.1176,0.3054,0.1561,0.4209\}$. The risk level is evaluated as level $C_{3}$ by CDRC, while the risk level is evaluated as level $C_{4}$ by TMMP.

The evaluation vectors using UME and AHP of all the 37 underground goafs, as well as the risk levels evaluated by CDRC and TMMP, are listed in Table 7. The comparison results for risk levels evaluated by CDRC and TMMP of 37 underground goafs are shown in Figure 7.
3.3. The Results for Ranking the Order of Underground Goafs. As $I_{k}$ is the score value of $C_{k}$ and the risk level $C_{k}$ is safer than $C_{k+1}$, it can be assumed that $I_{1}=1, I_{2}=2, I_{3}=3$, and $I_{4}=4$. Then the uncertainty important degree $q$ of the underground goaf $R$ can be solved according to (13). The uncertainty important degree of UME is represented as $q_{\mathrm{UME}}$, whereas the uncertainty important degree of AHP is represented as $q_{\mathrm{AHP}}$. The results of $q_{\mathrm{UME}}$ and $q_{\mathrm{AHP}}$ are shown in Figure 8. Based on the calculation results, we can rank the order of risk degree for 37 underground goafs from lower to higher, which is $R_{31}, R_{12}, R_{9}, R_{29}, R_{27}, R_{26}, R_{11}, R_{24}, R_{14}$, 


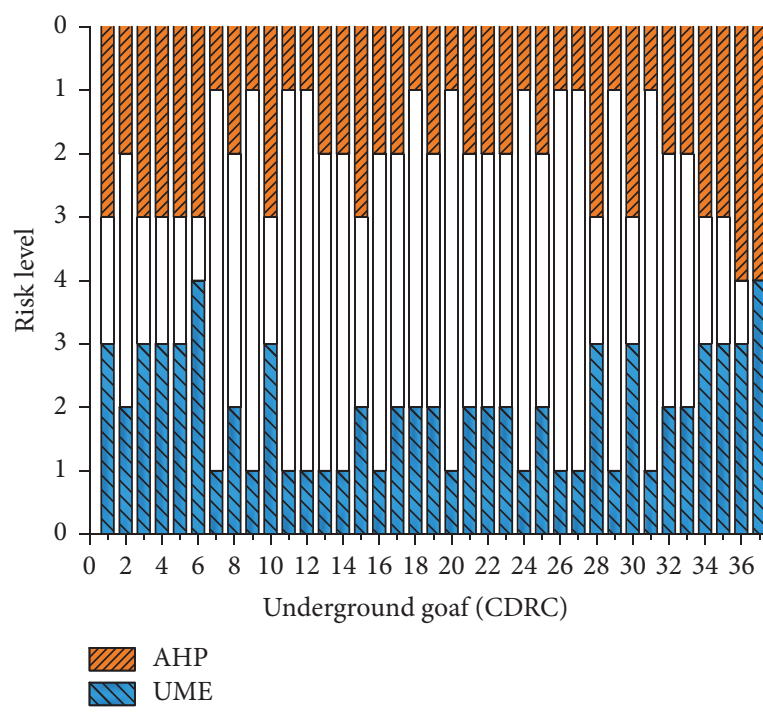

(a)

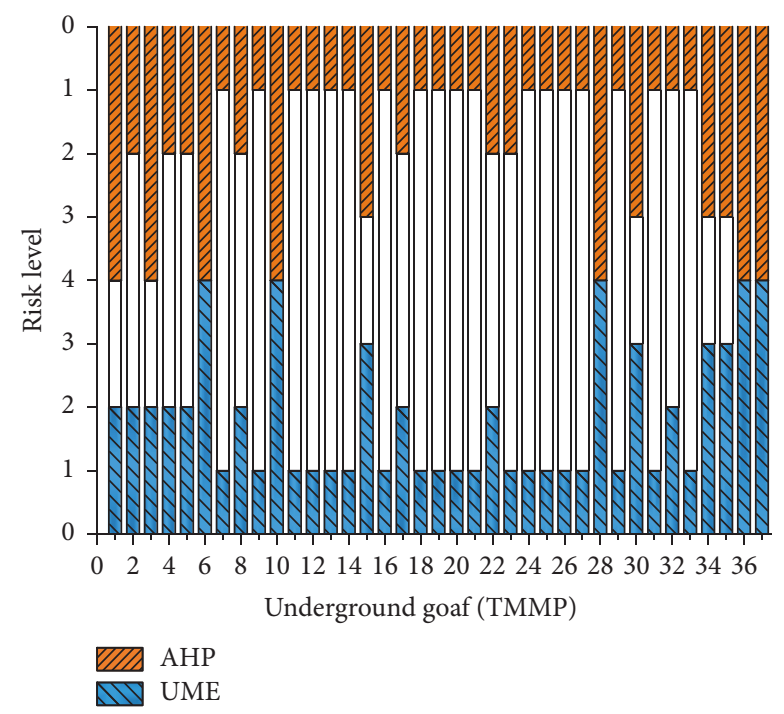

(b)

FIGURE 7: The comparison results for risk levels of 37 underground goafs. The graph (a) shows the risk levels of underground goafs using CDRC, and the graph (b) shows the risk levels using TMMP, where the blue part represents the risk levels of UME and the orange part represents the risk levels of AHP.

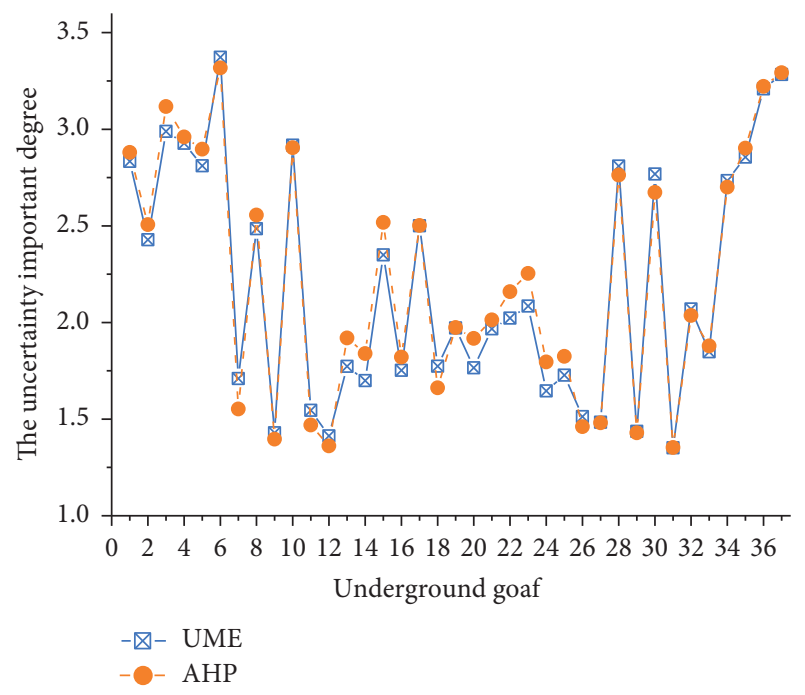

FIGURE 8: The comparison results for the uncertainty important degree of 37 underground goafs using UME and AHP, where the blue symbols represent values of $q_{\mathrm{UME}}$ and the orange symbols represent values of $q_{\mathrm{AHP}}$.

$R_{7}, R_{25}, R_{16}, R_{20}, R_{13}, R_{18}, R_{33}, R_{21}, R_{19}, R_{22}, R_{32}, R_{23}, R_{15}$, $R_{2}, R_{8}, R_{17}, R_{34}, R_{30}, R_{28}, R_{5}, R_{1}, R_{35}, R_{10}, R_{4}, R_{3}, R_{36}, R_{37}$, and $R_{6}$ for both UME and AHP. It is proved that UME and AHP have the similar ability and effect for ranking the order of risk degree. Furthermore, the ranking results can provide theoretical and reasonable guidance for the management of underground goafs. Actually, it is difficult to manage numerous underground goafs at the same time due to the great need of time, manpower, and environmental factors. Therefore, the underground goaf of higher risk degree can be managed firstly according to the order of risk degree. As a result, it is feasible to manage underground goafs reasonably without influencing the normal production.

\section{Discussion}

For the risk levels of underground goafs to be evaluated, there are 4 coupled methods, which are UME-CDRC, UMETMMP, AHP-CDRC, and AHP-TMMP, respectively. Table 8 shows the underground goafs of four risk levels with 4 coupled methods.

It is obvious that the order of risk degree is higher and the risk level of the underground goaf is higher. As the ranking results are the same for both UME and AHP, we can arrange all the underground goafs along a straight horizontal line from the lower risk degree to the higher risk degree, which is shown in Section 3.3. Then, we can divide this straight line into four sets $D_{1}, D_{2}, D_{3}$, and $D_{4}$ by setting three dividing lines artificially. In addition, the setting of three dividing lines is different based on the method to be analyzed. Also, the setting of dividing lines should be the optimal for every method. Therefore, there will be four sets of all the underground goafs with every method. Then, the underground goafs of four sets can be compared to the underground goafs of four risk levels quantitatively. The results shown in Table 8 are taken as standard data. Compared to the underground goafs of four sets $D_{1}, D_{2}, D_{3}$, and $D_{4}$, the detailed evaluation criteria are stated as follows:

(i) If the risk level of an underground goaf is equal to the level of the divided four sets, then the score value for the underground goaf is 0 .

(ii) If the difference between the risk level of an underground goaf and the level of the divided four sets is 
TABLE 8: The underground goafs of four risk levels with 4 coupled methods.

\begin{tabular}{|c|c|c|c|c|}
\hline \multirow{2}{*}{ Risk level } & \multicolumn{4}{|c|}{ Underground goafs using 4 coupled methods } \\
\hline & UME-CDRC & UME-TMMP & AHP-CDRC & AHP-TMMP \\
\hline$C_{1}$ & $\begin{array}{l}R_{7}, R_{9}, R_{11}, R_{12}, R_{13}, \\
R_{14}, R_{16}, R_{20}, R_{24}, R_{26}, \\
\quad R_{27}, R_{29}, R_{31}\end{array}$ & $\begin{array}{l}R_{7}, R_{9}, R_{11}, R_{12}, R_{13}, \\
R_{14}, R_{16}, R_{18}, R_{19}, R_{20} \\
R_{21}, R_{23}, R_{24}, R_{25}, R_{26} \\
\quad R_{27}, R_{29}, R_{31}, R_{33}\end{array}$ & $\begin{array}{c}R_{7}, R_{9}, R_{11}, R_{12}, R_{18} \\
R_{20}, R_{24}, R_{26}, R_{27}, R_{29} \\
R_{31}\end{array}$ & $\begin{array}{l}R_{7}, R_{9}, R_{11}, R_{12}, R_{13}, \\
R_{14}, R_{16}, R_{18}, R_{19}, R_{20}, \\
R_{21}, R_{24}, R_{25}, R_{26}, R_{27} \\
\quad R_{29}, R_{31}, R_{32}, R_{33}\end{array}$ \\
\hline$C_{2}$ & $\begin{array}{c}R_{2}, R_{8}, R_{15}, R_{17}, R_{18}, \\
R_{19}, R_{21}, R_{22}, R_{23}, R_{25}, \\
R_{32}, R_{33}\end{array}$ & $\begin{array}{c}R_{1}, R_{2}, R_{3}, R_{4}, R_{5}, R_{8} \\
\quad R_{17}, R_{22}, R_{32}\end{array}$ & $\begin{array}{l}R_{2}, R_{8}, R_{13}, R_{14}, R_{16}, \\
R_{17}, R_{19}, R_{21}, R_{22}, R_{23}, \\
\quad R_{25}, R_{32}, R_{33}\end{array}$ & $\begin{array}{c}R_{2}, R_{4}, R_{5}, R_{8}, R_{17} \\
R_{22}, R_{23}\end{array}$ \\
\hline$C_{3}$ & $\begin{array}{c}R_{1}, R_{3}, R_{4}, R_{5}, R_{10} \\
R_{28}, R_{30}, R_{34}, R_{35}, R_{36}\end{array}$ & $R_{15}, R_{30}, R_{34}, R_{35}$ & $\begin{array}{l}R_{1}, R_{3}, R_{4}, R_{5}, R_{6}, R_{10} \\
R_{15}, R_{28}, R_{30}, R_{34}, R_{35}\end{array}$ & $R_{15}, R_{30}, R_{34}, R_{35}$ \\
\hline$C_{4}$ & $R_{6}, R_{37}$ & $R_{6}, R_{10}, R_{28}, R_{36}, R_{37}$ & $R_{36}, R_{37}$ & $\begin{array}{c}R_{1}, R_{3}, R_{6}, R_{10}, R_{28}, \\
R_{36}, R_{37}\end{array}$ \\
\hline
\end{tabular}

TABLE 9: The four sets and the corresponding final score values of every coupled method.

\begin{tabular}{|c|c|c|c|c|c|c|c|c|}
\hline \multirow{2}{*}{ Sets } & \multicolumn{7}{|c|}{ Comparison results of 4 coupled methods } & \multirow[b]{2}{*}{ Score } \\
\hline & UME-CDRC & Score & UME-TMMP & Score & AHP-CDRC & Score & AHP-TMMP & \\
\hline$D_{1}$ & $\begin{array}{c}R_{31}, R_{12}, R_{9} \\
R_{29}, R_{27}, R_{26} \\
R_{11}, R_{24}, R_{14} \\
R_{7}, R_{25}, R_{16} \\
\quad R_{13}, R_{20}\end{array}$ & -1 & $\begin{array}{c}R_{31}, R_{12}, R_{9} \\
R_{29}, R_{27}, R_{26} \\
R_{11}, R_{24}, R_{14} \\
R_{7}, R_{25}, R_{16} \\
R_{20}, R_{13}, R_{18} \\
R_{33}, R_{19}, R_{21}\end{array}$ & 0 & $\begin{array}{l}R_{31}, R_{12}, R_{9} \\
R_{29}, R_{27}, R_{26} \\
\quad R_{11}, R_{24}\end{array}$ & 0 & $\begin{array}{c}R_{31}, R_{12}, R_{9}, \\
R_{29}, R_{27}, R_{26}, \\
R_{11}, R_{24}, R_{14}, \\
R_{7}, R_{25}, R_{16}, \\
R_{20}, R_{13}, R_{18}, \\
R_{33}, R_{21}, R_{19}, \\
\quad R_{22}, R_{32}\end{array}$ & -1 \\
\hline$D_{2}$ & $\begin{array}{c}R_{18}, R_{33}, R_{21}, \\
R_{19}, R_{22}, R_{32}, \\
R_{23}, R_{15}, R_{2}, \\
R_{8}, R_{17}\end{array}$ & 0 & $\begin{array}{c}R_{22}, R_{32}, R_{23} \\
R_{15}, R_{2}, R_{8} \\
R_{17}\end{array}$ & -2 & $\begin{array}{c}R_{14}, R_{7}, R_{25}, \\
R_{16}, R_{20}, R_{13}, \\
R_{18}, R_{33}, R_{21}, \\
R_{19}, R_{22}, R_{32}, \\
R_{23}, R_{15}, R_{2}, \\
\quad R_{8}, R_{17}\end{array}$ & -4 & $\begin{array}{c}R_{23}, R_{15}, R_{2} \\
R_{8}, R_{17}\end{array}$ & -1 \\
\hline$D_{3}$ & $\begin{array}{c}R_{34}, R_{30}, R_{28} \\
R_{5}, R_{1}, R_{35} \\
R_{10}, R_{4}, R_{3} \\
\quad R_{36}\end{array}$ & 0 & $\begin{array}{c}R_{34}, R_{30}, R_{28} \\
R_{5}, R_{1}, R_{35} \\
R_{10}, R_{4}, R_{3}\end{array}$ & -6 & $\begin{array}{c}R_{34}, R_{30}, R_{28} \\
R_{5}, R_{1}, R_{35} \\
R_{10}, R_{4}, R_{3}\end{array}$ & 0 & $\begin{array}{c}R_{34}, R_{30}, R_{28} \\
R_{5}, R_{1}, R_{35}\end{array}$ & -3 \\
\hline$D_{4}$ & $R_{37}, R_{6}$ & 0 & $R_{36}, R_{37}, R_{6}$ & 0 & $R_{36}, R_{37}, R_{6}$ & -1 & $\begin{array}{l}R_{10}, R_{4}, R_{3}, \\
R_{36}, R_{37}, R_{6}\end{array}$ & -2 \\
\hline Final score & -1 & & -8 & & -5 & & -7 & \\
\hline
\end{tabular}

equal to 1 , then the score value for the underground goaf is -1 .

(iii) If the difference between the risk level of an underground goaf and the level of the divided four sets is equal to 2 , then the score value for the underground goaf is -2 .

(iv) If the difference between the risk level of an underground goaf in and the level of the divided four sets is equal to 3 , then the score value for the underground goaf is -3 .

If the final score value is higher, it means that the corresponding method is more reasonable and suitable for the evaluation of risk level. UME-CDRC is taken as an example: the first dividing line is set between $R_{13}$ and $R_{18}$, the second dividing line is set between $R_{17}$ and $R_{34}$, and the third dividing line is set between $R_{36}$ and $R_{37}$. Therefore, there are $D_{1}=\{31,12,9,29,27,26,11,24,7,25,16,20,13\}, D_{2}=\{18$, $33,21,19,22,32,23,15,2,8,17\}, D_{3}=\{34,30,28,5,1,35,10$, $4,3,36\}$, and $D_{4}=\{37,6\}$. Compared to the risk levels of UME-CDRC shown in Table 8, it is obvious that only the risk level of the underground goaf $R_{25}$ is different from the standard data, where the difference is equal to 1 . Then, the final score value of UME-CDRC is determined as -1 . Similarly, the final score value of UME-TMMP, AHP-CDRC, and AHP-TMMP can be solved as $-8,-5$, and -7 , respectively. The four sets and the corresponding score values of every method are listed in Table 9.

Obviously, the score value of UME-CDRC is the maximum among the 4 coupled methods. As a result, UMECDRC is the most reasonable method for the evaluation of underground goafs risk degrees. Through the comparisons 
of UME-CDRC and UME-TMMP, AHP-CDRC, and AHPTMMP, the score value of UME-CDRC is much smaller than UME-TMMP and the score value of AHP-CDRC is smaller than AHP-TMMP. Thus, it can be concluded that CDRC is more reasonable than TMMP. Sometimes, the difference between the greatest weight and the second greatest weight in the evaluation vector is little. In this case, the risk level evaluated through TMMP will not be reasonable and reliable. On the contrary, CDRC is suitable for evaluation of underground goafs risk levels whatever the difference between the greatest weight and the second greatest weight. As for AHP, it is more subjective than UME because the process of establishing the hierarchical model and the determination of weights for evaluation indexes are more subjective. The evaluation vector of UME is determined through the measured values, which is more objective. Therefore, it is concluded that UME-CDRC is reasonable for evaluation of underground goafs risk degrees in the practical engineering application.

\section{Conclusions}

As the special characteristics of underground goafs are with irregular geometric shapes, concealed locations, and huge amount, they have caused numerous safety accidents and destructive disasters, which influence the normal production in mines and the surrounding environment. Therefore, the evaluation of underground goafs risk degrees is an urgent and significant problem. In this paper, the theories of UME and AHP were applied to comprehensively evaluate the risk levels of underground goafs. According to the hydrogeological conditions, mining status, and engineering parameters, 14 factors were selected to establish the evaluation index system. Based on the estimated and measured data, the semiridge distribution is selected as the single index measurement functions. Then, the single index measurement values were solved quantitatively according to the single index measurement functions. Furthermore, the weights of evaluation vector were determined by applying the entropy theory and AHP. Once the evaluation vectors of UME and AHP were obtained, the risk levels of underground goafs can be evaluated through the recognition criteria CDRC and TMMP. Also, the order of risk degree can be ranked per the values of uncertainty important degree. Combining the calculation methods UME and AHP with the recognition criteria CDRC and TMMP, there are 4 coupled methods UME-CDRC, UME-TMMP, AHP-CDRC, and AHP-TMMP. The data of underground goafs in Dabaoshan mine were used to evaluate the risk levels using the 4 coupled methods, as well as ranking the order of risk degree. On account of the ranked order, it is proved that UME-CDRC is the most reasonable method through both quantitative and qualitative analysis. Results show that UMECDRC not only can evaluate the underground goafs risk degrees reasonably, but also can rank the order of risk degree, which insures that the most dangerous underground goaf can be managed at the first time to reduce the probability of accidents. The developed UME-CDRC provides a reasonable and reliable methodology to evaluate the underground goafs risk degrees, which is not only a beneficial complement for the management methods of underground goafs, but also a big improvement for environmental protection as well as for the sustained development of green mining.

\section{Conflicts of Interest}

The authors declare that there are no conflicts of interest regarding the publication of this paper.

\section{Acknowledgments}

The authors wish to acknowledge financial support from the State Key Research Development Program of China (2016YFC0600706), the National Basic Research Program of China (2015CB060200), National Natural Science Foundation of China (41630642, 51504288), China Postdoctoral Science Foundation (2015M570688, 2016T90639), The Young Elite Scientists Sponsorship Program by CAST (2016QNRC001), and Innovation-Driven Project of Central South University (2016CXS001).

\section{References}

[1] L. J. Dong, J. Wesseloo, Y. Potvin, and X. B. Li, "Discriminant models of blasts and seismic events in mine seismology," International Journal of Rock Mechanics and Mining Sciences, vol. 86, pp. 282-291, 2016.

[2] L. Dong, J. Wesseloo, Y. Potvin, and X. Li, "Discrimination of mine seismic events and blasts using the fisher classifier, naive bayesian classifier and logistic regression," Rock Mechanics and Rock Engineering, vol. 49, no. 1, pp. 183-211, 2016.

[3] M. Bukowska, "The rockbursts in the Upper Silesian Coal Basin in Poland," Journal of Mining Science, vol. 48, no. 3, pp. 445-456, 2012.

[4] X. T. Feng, S. Webber, and M. U. Ozbay, "Neural network modeling on assessing rockburst risks for South African deep gold mines," Transactions of Nonferrous Metals Society of China, vol. 8, no. 2, pp. 1-7, 1998.

[5] M. S. Diederichs and P. K. Kaiser, "Rock instability and risk analyses in open stope mine design," Canadian Geotechnical Journal, vol. 33, no. 3, pp. 431-439, 1996.

[6] X. Li, S. J. Wang, T. Y. Liu, and F. S. Ma, "Engineering geology, ground surface movement and fissures induced by underground mining in the Jinchuan Nickel Mine," Engineering Geology, vol. 76, no. 1-2, pp. 93-107, 2004.

[7] L. Dong, W. Shu, X. Li, G. Han, and W. Zou, “Three Dimensional Comprehensive Analytical Solutions for Locating Sources of Sensor Networks in Unknown Velocity Mining System," IEEE Access, vol. 5, pp. 11337-11351, 2017.

[8] State Administration of Work Safety and State Administration of Coal Mine Safety, State Technological Development Programming of Work Safety -Non-Coal Mine Domain Research Bulletin, State Administration of Work Safety, State Administration of Coal Mine Safety, Beijing, China, 2010.

[9] H. Ma, J. Wang, and Y. Wang, "Study on mechanics and domino effect of large-scale goaf cave-in," Safety Science, vol. 50, no. 4, pp. 689-694, 2012.

[10] Y.-X. Hu and X.-B. Li, "Bayes discriminant analysis method to identify risky of complicated goaf in mines and its application," Transactions of Nonferrous Metals Society of China, vol. 22, no. 2, pp. 425-431, 2012. 
[11] R. G. Corbett, "Effects of coal mining on ground and surface water quality, Monongalia County, West Virginia," Science of the Total Environment, The, vol. 8, no. 1, pp. 21-38, 1977.

[12] X. Huang, M. Sillanpää, E. T. Gjessing, S. Peräniemi, and R. D. Vogt, "Environmental impact of mining activities on the surface water quality in Tibet: Gyama valley," Science of the Total Environment, vol. 408, no. 19, pp. 4177-4184, 2010.

[13] F. J. Martín Peinado, A. Romero-Freire, I. García Fernández, M. Sierra Aragón, I. Ortiz-Bernad, and M. Simón Torres, "Longterm contamination in a recovered area affected by a mining spill," Science of the Total Environment, vol. 514, pp. 219-223, 2015.

[14] P. Huang and X. Wang, "Applying environmental isotope theory to groundwater recharge in the jiaozuo mining area, china," Geofluids, vol. 2017, Article ID 9568349, 11 pages, 2017.

[15] P. Achtziger-Zupančič, S. Loew, A. Hiller, and G. Mariethoz, "3D fluid flow in fault zones of crystalline basement rocks (Poehla-Tellerhaeuser Ore Field, Ore Mountains, Germany)," Geofluids, vol. 16, no. 4, pp. 688-710, 2016.

[16] X. Shi, F. Jiang, Z. Feng, B. Yao, H. Xu, and J. Wu, "Characterization of the regional groundwater quality evolution in the North Plain of Jiangsu Province, China," Environmental Earth Sciences, vol. 74, no. 7, pp. 5587-5604, 2015.

[17] X. Shi, S. Jiang, H. Xu, F. Jiang, Z. He, and J. Wu, "The effects of artificial recharge of groundwater on controlling land subsidence and its influence on groundwater quality and aquifer energy storage in Shanghai, China," Environmental Earth Sciences, vol. 75, no. 3, article 195, 2016.

[18] X. B. Li, D. Y. Li, G. Y. Zhao, Z. L. Zhou, and F. Q. Gong, "Detecting, disposal and safety evaluation of the underground goaf in metal mines," Journal of Mining and Safety Engineering, vol. 23, pp. 24-29, 2006.

[19] Future net, An earthquake with the magnitude 3.1 occurred in Pingyi County, Shandong Province http://news.k618.cn/society/ shwx//_7017577.html.

[20] The first financial net, Thousands of collapse pits occurred in the Hulun Buir prairie. http://www.afinance.cn/new/gncj//488504 .html.

[21] Xinhuanet, The groundwater inrush accident occurred at the mines in Nandan County, Guangxi Province. http://news .xinhuanet.com/china/2001-08/08/content_76694.htm.

[22] X. B. Li, L. J. Dong, G. Y. Zhao et al., "Stability analysis and comprehensive treatment methods of landslides under complex mining environment-a case study of Dahu landslide from Linbao Henan in China," Safety Science, vol. 50, no. 4, pp. 695704, 2012.

[23] D. J. Yancey, M. G. Imhof, J. E. Feddock, and T. Gresham, "Analysis and application of coal-seam seismic waves for detecting abandoned mines," Geophysics, vol. 72, no. 5, pp. M7-M15, 2007.

[24] L. Dong and X. Li, "Comprehensive models for evaluating rockmass stability based on statistical comparisons of multiple classifiers," Mathematical Problems in Engineering, vol. 2013, Article ID 395096, 9 pages, 2013.

[25] S. Lou, B. Yang, and Z. Luo, “Three-dimensional information acquisition and visualization application in goaf," Procedia Engineering, vol. 84, pp. 860-867, 2014.

[26] Y. Sun, X. Zhang, W. Mao, and L. Xu, "Mechanism and stability evaluation of goaf ground subsidence in the third mining area in Gong Changling District, China," Arabian Journal of Geosciences, vol. 8, no. 2, pp. 639-646, 2015.
[27] Z.-Q. Luo, C.-Y. Xie, J.-M. Zhou, N. Jia, X.-M. Liu, and H. Xu, "Numerical analysis of stability for mined-out area in multifield coupling," Journal of Central South University, vol. 22, no. 2, pp. 669-675, 2015.

[28] L. Nie, H. Wang, Y. Xu, and Z. Li, "A new prediction model for mining subsidence deformation: the arc tangent function model," Natural Hazards, vol. 75, no. 3, pp. 2185-2198, 2015.

[29] K. W. Mills, O. Garratt, B. G. Blacka, L. C. Daigle, A. C. Rippon, and R. J. Walker, "Measurement of shear movements in the overburden strata ahead of longwall mining," International Journal of Mining Science and Technology, vol. 26, no. 1, pp. 97102, 2016.

[30] B. Su, R. Malekian, J. Yu, X. Feng, and Z. Liu, "Electrical Anisotropic Response of Water Conducted Fractured Zone in the Mining Goaf," IEEE Access, vol. 4, pp. 6216-6224, 2016.

[31] B. Su, J. Yu, and C. Sheng, "Borehole electromagnetic method for exploration of coal mining goaf," Elektronika ir Elektrotechnika, vol. 22, no. 4, pp. 37-40, 2016.

[32] J.-H. Hu, J.-L. Shang, K.-P. Zhou et al., "Hazard degree identification of goafs based on scale effect of structure by RS-TOPSIS method," Journal of Central South University, vol. 22, no. 2, pp. 684-692, 2015.

[33] K.-L. Du, "Clustering: A neural network approach," Neural Networks, vol. 23, no. 1, pp. 89-107, 2010.

[34] Q.-H. Wu, S.-M. Wan, and W.-X. Peng, "A comprehensive evaluation method about stability of polylaminate goafs," Journal of Central South University (Science and Technology), vol. 43, pp. 2324-2330, 2012.

[35] M. Shao, Z. Gong, and X. Xu, "Risk assessment of rainstorm and flood disasters in China between 2004 and 2009 based on gray fixed weight cluster analysis," Natural Hazards, vol. 71, no. 2, pp. 1025-1052, 2014.

[36] P. M. Orencio and M. Fujii, "A localized disaster-resilience index to assess coastal communities based on an analytic hierarchy process (AHP)," International Journal of Disaster Risk Reduction, vol. 3, no. 1, pp. 62-75, 2013.

[37] G. Y. Wang, "Uncertainty information and its mathematical treatment," Journal of Harbin Architecture and Engineering Institute, vol. 23, pp. 52-58, 1990.

[38] H. J. He, Y. M. Yan, C. X. Qu, and Y. Fan, "Study and application on stability classification of tunnel surrounding rock based on uncertainty measure theory," Mathematical Problems in Engineering, vol. 2014, Article ID 626527, 5 pages, 2014.

[39] Y. Duan, Fuzzy synthetic accessment of the hazard degree of underground goaf disaster [M.S. dissertation], Safety Engineering, Central South University, Changsha, China, 2005. 

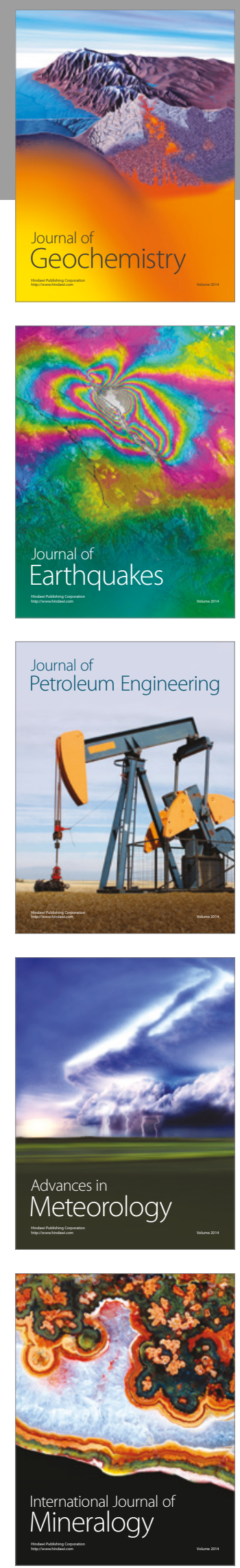
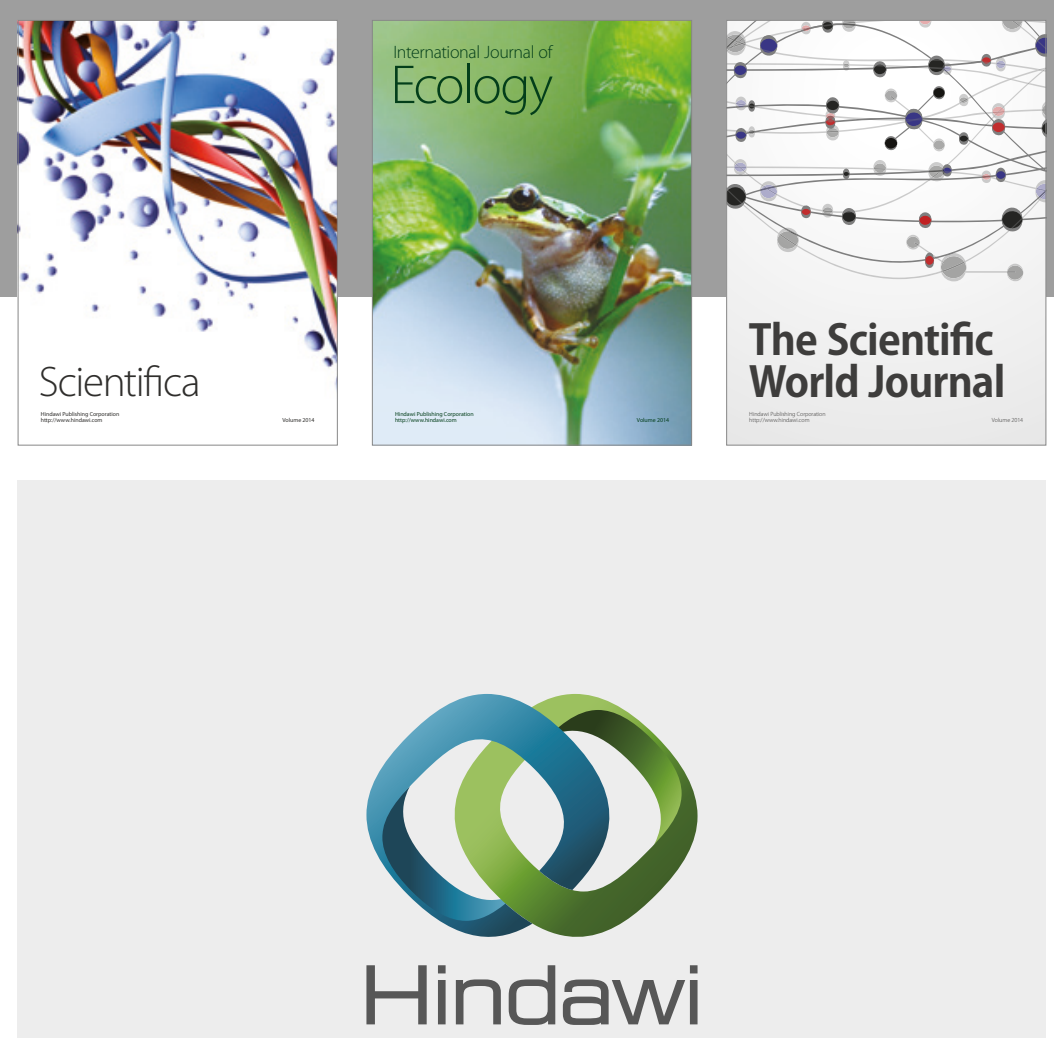

Submit your manuscripts at

https://www.hindawi.com
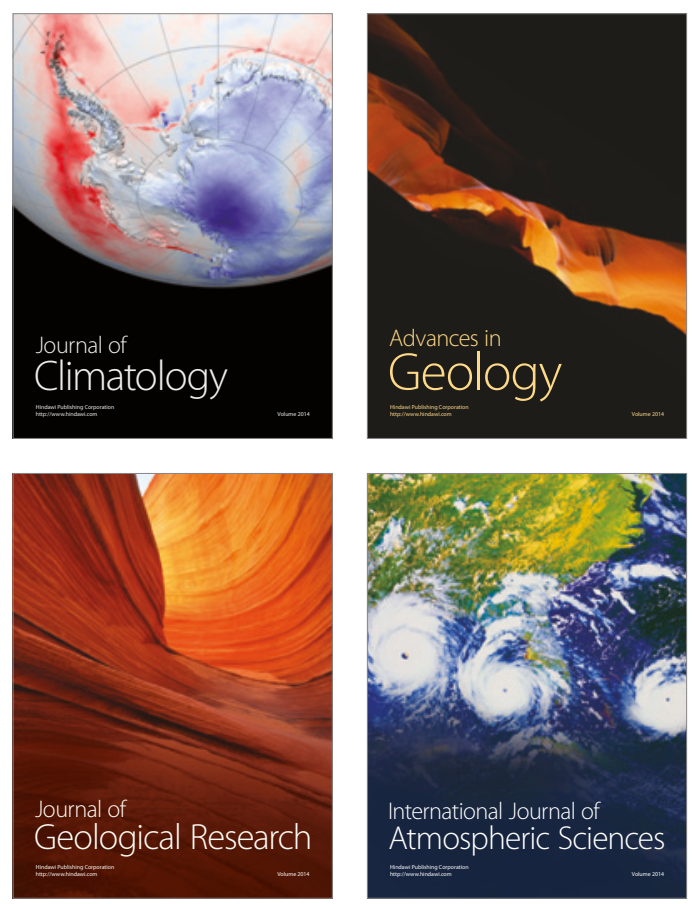

The Scientific

World Journal
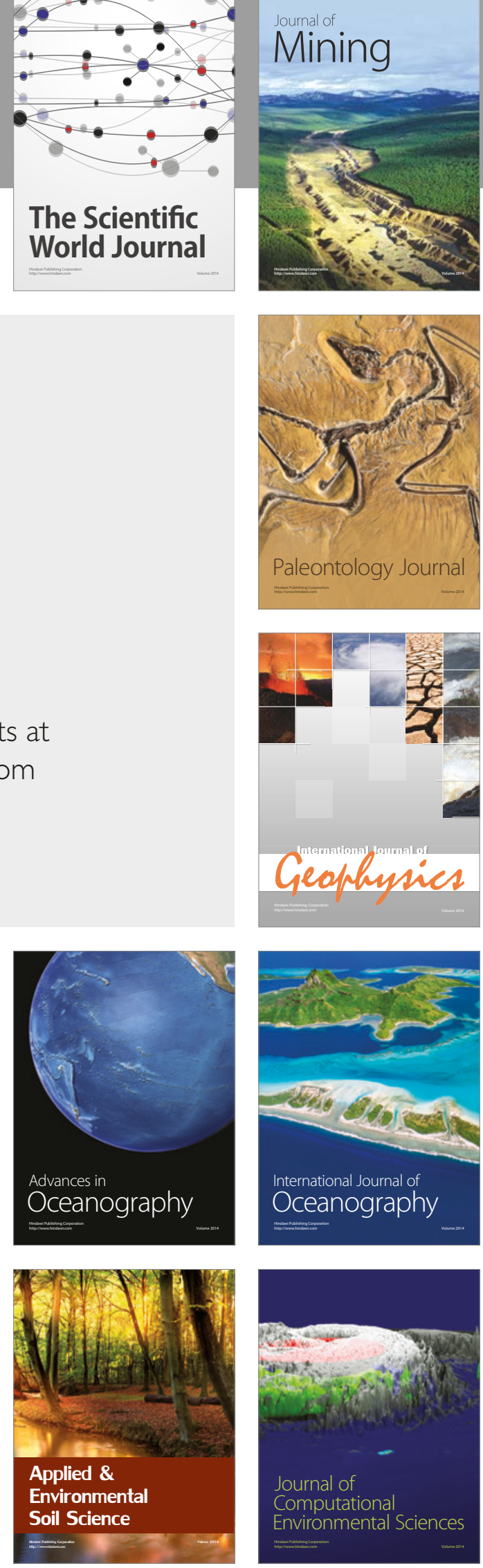